\title{
Experiments on the Fundamental Mechanisms of Boiling Heat Transfer
}

\author{
H. Auracher \\ Institut für Energietechnik \\ Technische Universität Berlin \\ Marchstr. 18, KT 1, D-10587 Berlin, Germany \\ auracher@iet.tu-berlin.de \\ M. Buchholz \\ Robert Bosch GmbH (DS/EDS3) \\ Wernerstr. 51, 70469 Stuttgart \\ Martin.Buchholz@de.bosch.com
}

The lecture presents a survey of results found by the author and his team during recent years. ${ }^{a}$. An experimental technique for precise and systematic measurements of entire boiling curves under steady-state and transient conditions has been developed. Pool boiling experiments for well wettingfluids and fluids with a larger contact angle (FC-72, isopropanol, water) yield single and reproducible boiling curves if the system is clean. However, even minimal deposits on the surface change the heat transfer characteristic and shift the boiling curve with each test run. The situation is different under transient conditions: heating and cooling transiens yield different curves even on clean surfaces. Measurements with microsensors give an insight in the two-phase dynamics above the heating surface and the temperature field dynamics above and beneath the surface. Microthermocouples (38 $\mu$ m diameter) enbedded in the heater (distance to the surface $3.6 \mu \mathrm{m}$ ), a micro optical probe (tip diameter $\sim 1.5 \mu \mathrm{m}$ ) and a microthermocouple probe (tip diameter $\sim 16 \mu \mathrm{m}$ ), both moveable above the heater surface, are used for these studies. In nucleate boiling, very localized and rapid temperature drops are observed indicating high heat fluxes at the bottom of the bubbles. Already before reaching the critical heat flux $(\mathrm{CHF})$, hot spots occur the size of which increases towards the Leidenfrost point. In the entire transition boiling regime wetting events are observed, but no ones in film boiling. In low heat flux nucleate boiling very small vapor superheats exist in the bubbles and strong superheats in the surrounding liquid. This characteristic change continuously with increasing wall superheat: the liquid surrounding the vapor approaches saturation whereas the vapor becomes more and more superheated. In film boiling the bubbles leaving the vapor film can reach superheats of $30 \mathrm{~K}$ or more near the surface (e.g. for isopropanol). The optical probes confirm a liquid rich layer near the surface between nucleate boiling and high heat flux transition boiling. The void fraction in the layer increases continuously with the distance to the surface until a maximum value which seems to be linked to the bubble departure diameter.

Via the microsensor-data new approaches for heat transfer models on a mechanistic basis are proposed. An interfacial-area-density model enables the prediction of entire boiling curves. Furthermore the concept of a reaction-diffusion model is presented to predict CHF. Here the triggering of $\mathrm{CHF}$ is due to an instability of dry spots on the heating surface. Many aspects of the extremely complex mechanisms of boiling are, however, still not sufficiently understood. The problems should be tackled from both the experimental and the theoretical end and both approaches should be closely linked.

Keywords: Boiling Curve, Transient Boiling, Microthermocouple, Microthermocouple Probe, Micro Optical Probe

\section{Introduction}

In spite of numerous studies on boiling during the last decades, understanding of this complex process is still unsatisfactory. Nevertheless significant progress has been achieved in recent years.This is because more sophisticated experimental techniques and data acquisition systems as well as significantly improved mathematical tools are now available. Hence, our ability to explore the basic mechanisms of boiling has been improved and those results are increasingly used to develop physically based heat transfer models. They are more generally valid than empirical correlations and, last but not least, a deeper knowledge of the governing physical mechanisms gives us the chance to develop enhanced heat transfer surfaces systematically and not by trial and error methods.

The governing mechanisms of boiling take place very near to the surface. If a thin electrically-heated plate is used as test heater, bubble and vapor spot dynamics at the surface can be studied nonintrusively by liquid crystals (kenning and Yan) or infraredthermography on the rear surface. However, liquid crystal

Presented at ENCIT2004 - 10th Brazilian Congress of Thermal Sciences and Engineering, Nov. 29 -- Dec. 03, 2004, Rio de Janeiro, RJ, Brazil.

Technical Editor: Atila P. Silva Freire.

a The results are also published in more detailed versions in the articles: Auracher and Marquardt, 2004; Buchholz et al., 2004; Buchholz et al., 2005 and some earlier ones cited in the list of references thermography has a limited temporal resolution (Golobic et al., 2004). This shortcoming might be overcome by highspeed infrared thermography. But even though, validation of a boiling model also needs data on the two-phase characteristics above the surface, such as information about bubble growth, bubble coalescence etc.. Moreover, real heating surfaces are thick and the boiling mechanism may differ from the one on thin foils, see (Kleen, 1984 and BarCohen et al., 2003), for example. In particular, the temperature field dynamics in the heater body plays a role and should be taken into account. Hence, a complex three-dimensional multiphase flow problem connected to a three-dimensional heat conduction problem has to be tackled.

If thick heaters, as used in practical applications, are to be studied as in the present report, nonintrusive temperature measurement techniques such as liquid crystals or thermography are not applicable. Other nonintrusive techniques for investigating the two-phase flow characteristics like high-speed video, x-ray attenuation etc. are of limited benefit because these methods cannot access the most important parameters determining two-phase flow in the region of high void fractions. Miniaturized sensors are preferable if they do not significantly disturb the processes taking place inside and above the heater. This was the focus of our studies in recent years.

First an experimental technique is presented which enables a precise and systematic measurement of entire boiling curves under steady-state and transient conditions. This technique is applied, in the first step, to find out whether boiling curves exhibit a hysteresis in the transition region under steady-state conditions. To find an 
answer, steady-state experiments are carried out with well wetting fluids and fluids with a larger contact angle (FC-72, isopropanol, water). Moreover, boiling curves under transient heating and cooling conditions are presented for FC-72.

A precise technique to determine entire boiling curves is a necessary prerequisite to study the boiling mechanisms in the different boiling regimes. Results of this kind are presented in a second part of the present report. Microoptical probes are applied to study the two-phase behavior above the heating surface in the different boiling regions. Microthermocouples beneath the surface are used to measure temperature fluctuations caused by the twophase dynamics above the surface. In addition a microthermocouple probe is applied to measure the vapor and liquid temperature fluctuations in the two-phase region above the heating surface.

All the obtained results lead to some conclusions on the mechanisms of boiling such as the macrolayer configuration, the dry spot size and dynamics, the nucleation site density etc. These findings and others from the literature are used as input to physically based boiling heat transfer models which are proposed in the last part. Firstly an interfacial-area-density model is proposed to determine entire boiling curves based on data from the optical probes. Secondly a reaction-diffusion model is presented to predict critical heat flux (CHF). It needs information about the dry spot behavior on the heating surface.

\section{Experimental Facilities}

\section{Test Loop}

A scheme of the test loop is depicted in Fig. (1). The main components of the test facility are the boiling vessel (diameter 209 $\mathrm{mm}$, height $332 \mathrm{~mm}$ ), the vapor generator and the condenser. The maximum operation pressure of the test loop for flammable test fluids is $0.7 \mathrm{MPa}$, otherwise 1.0 MPa. A filter loop with a heat exchanger, a hermetic centrifugal pump and a filter with an absolute removal rating of $0.2 \mu \mathrm{m}$ can be used to remove small particles from the test fluid. Four sightglasses at heater level and two sightglasses at an angle of $45^{\circ}$ allow observation of the boiling process. A recirculated temperature controlled bath filled with Thermogen 1693 (Clariant Company), a synthetic heat transfer fluid, is used to maintain constant saturation conditions in the test vessel via two tube coils. The vapor generator provides a basic load for the pressure controlled condenser. It also reheats potentially subcooled liquid from the condenser to preserve constant saturation state at the boiling vessel inlet. The condenser is cooled with a water/ethylene glycol mixture. Constant inlet conditions are realized by an electric heater and a heat exchanger, both temperature controlled. The coolant mass flow is controlled by a motorized control valve which is connected to a pressure control loop. It is realized on a PC (P III, $733 \mathrm{MHz}$ ) with the software LabView (National Instruments) and installed multifunction data acquisition cards. The output of the controller sets the position of a motorized coolant control valve. The probes are installed at the top of the vessel. They can be moved in xyz--direction. To avoid any contamination, the test loop is completely made from stainless steel, pickled, electropolished and passivated.

\section{Test Heaters}

\section{Model Based Heater Design}

For the design of the test heaters, several competing and contradicting design criteria have to be considered to allow for a save operation of the apparatus and to conduct meaningful boiling experiments. To meet these design objectives optimally a modelbased design approach has been applied which includes 2- and 3D FEM simulations of the temperature field and stability analyses of the controlled apparatus (more details in Blum et al., 1996; Buchholz et al., 2000; Hohl et al, 2001)

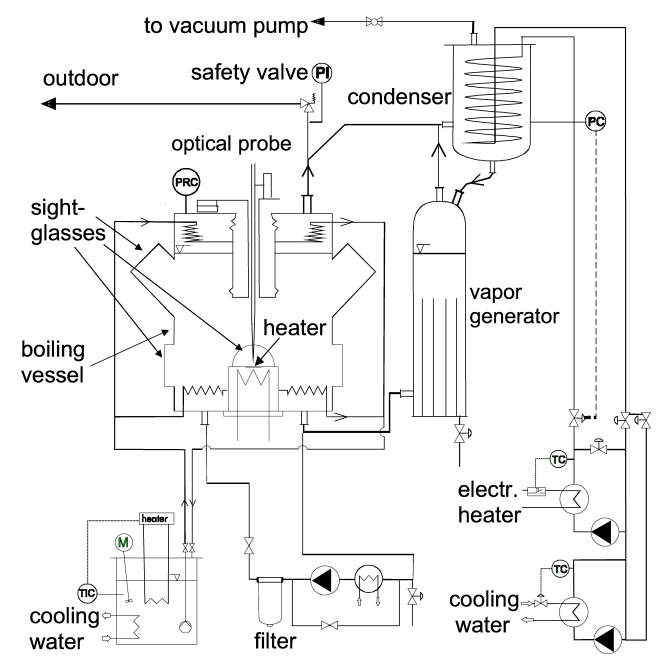

Figure 1. Test loop and heater section.

\section{Heater for Pool Boiling Experiments With Water and Isopropanol}

An outline of the heater section shows Fig. (2). The copper heater with surface diameter of 35 and $7 \mathrm{~mm}$ thickness is fixed in a stainless steel housing. The copper block is cylindrical in the top part and quadratic in the bottom part with the edges cut off (more details in Buchholz et al., 2000). The quadratic shape is needed to enable heating by a $25 \mu \mathrm{m}$ thick heating foil pressed onto the bottom. An aluminium nitride plate between foil and heater serves as electrical insulator. The maximum possible heat flux at the heater surface is $5.5 \mathrm{MW} / \mathrm{m}^{2}$ with a maximum heating current of $350 \mathrm{~A} .14$ K-type thermocouples $(\varnothing 0.25 \mathrm{~mm})$ with the tips $0.375 \mathrm{~mm}$ below the surface were implanted in the heater by electroplating. They are used for temperature control and the determination of the average surface temperature. 4 thermocouples are installed $1 \mathrm{~mm}$ above the bottom of the copper block. They are used for overtemperature protection. In addition to the K-Type thermocouples several microthermocouples are implanted in the copper block. The details are presented in chap. 2.5 .

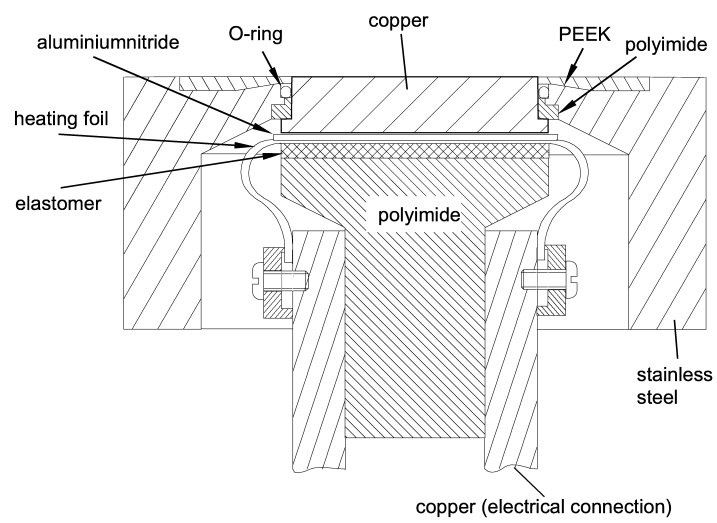

Figure 2. Heater for experiments with water and isopropanol. 


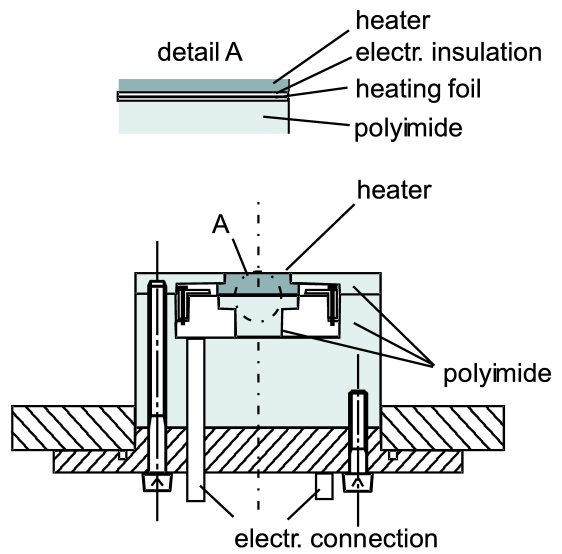

Figure 3. Heater (no. 2) for experiments with FC-72.

\section{Heater for Pool Boiling Experiments With FC-72}

Two heaters are used for the experiments with FC-72 $\left(\mathrm{C}_{6} \mathrm{~F}_{14}, 3-\right.$ $\mathrm{M}$ company), one for steady-state and the other for transient experiments. They are similar except for the size and the heating mode. For steady-state experiments a copper heater (no. 1) with 34 $\mathrm{mm}$ diameter and $10 \mathrm{~mm}$ thickness, DC-heated indirectly from the bottom by a sheathed resistance wire, was applied (more details in Hohl et al., 1998). For the transient experiments a heater (no. 2) with lower thermal inertia and higher maximum heat input was used (Fig. (2)). The design of this heater is similar to the one used for the water and isopropanol experiments (Fig. (2)). It consists of a $5 \mathrm{~mm}$ thick copper block, $20 \times 20 \mathrm{~mm}$ squared in the bottom part and cylindrical with $18.2 \mathrm{~mm}$ diameter in the top part. It is insulated $(\lambda=$ $0.22 \mathrm{~W} / \mathrm{m} / \mathrm{K}$ ) and sealed by polyimide. Heat losses through the polyimide block are small, hence one-dimensional heat conduction can be assumed. Three thermocouples of $0.25 \mathrm{~mm}$ outer diameter and a number of microthermocouples are also installed in heater no. 2 (more details in Hohl amd Auracher, 2000).

\section{Control Concept and Stability Analysis}

The wall temperature is controlled by measuring the temperature close to the boiling surface, comparing it to a setpoint value which is either constant in steady-state experiments or time-varying in transient experiments, feeding the difference signal into the controller and adjusting the power of the electric heating according to the controller output. The setpoint signal as well as the control law are implemented on a computer. More details for the steadystate and the transient experiments with FC-72 are presented by Hohl et al., 2001.

The access to the transition region in the case of water experiments and to a certain extent also in the isopropanol tests is more difficult than with FC-72 because of the high heat fluxes and the steep negative slope of the boiling curves. A stability analysis has been performed based on the Laplace domain transfer function model of the test heaters, i.e., the one-dimensional heat conduction equation and all control loop elements. Solving for the poles of the closed-loop system numerically, the stability limits of the controlled system can be found (more details in Blum et al., 1996).

\section{Data Acquisition of Boiling Curve Measurements}

\section{Water and Isopropanol Pool Boiling Experiments}

Heating voltage, heating current and amplified temperature signals of the K-type thermocouples are sampled with the data acquisition board PC30 (Meilhaus Electronic). For the isopropanol experiments, this card has been replaced by two DaqBoard2000 cards (IO-Tech). The sampling frequency for each channel is 100 $\mathrm{Hz}$.

Heater temperature control is realized by the digital signal processing board AT-DSP 2200 (National Instruments). The discrete PI-controller runs on the onboard DSP-processor. The total time between stimulus and response at the output of the card is 1.5 ms. The input heater temperature used for the temperature controller is the instantaneous average of 12 sheathed thermocouples in the test heater. The output voltage of the card is amplified and supplied to the heating foil. The surface superheat is calculated by correcting the time average of the temperature measured by thermocouples by the temperature difference between sensor location and heating surface, assuming a one-dimensional temperature field in the test heater. The same holds for the steady-state experiments with FC-72.

\section{FC-72 Experiments}

In the steady-state case data are sampled for $2 \mathrm{~s}$ for each point of the boiling curve. The entire boiling curve is recorded by successively raising or lowering the set-point value. In transient experiments, the controller must additionally track a prescribed temperature trajectory. Here, a ramp with the temporal gradient as the varied parameter and as a measure for transient dynamics is chosen. The sampling frequency for each channel is chosen to be $200 \mathrm{~Hz}$ during steady-state experiments, $500 \mathrm{~Hz}$ during slow transients up to $15 \mathrm{~K} / \mathrm{s}$ and $5000 \mathrm{~Hz}$ during fast transient runs. In transient experiments, both heat flux and temperature at the heater surface are calculated by means of an inverse heat conduction algorithm presented by Hohl et al., 2001.

\section{Microthermocouples (MTCs)}

Since even the smallest standard sheathed thermocouples cannot resolve the temperature fluctuations at the heater surface with sufficient accuracy with respect to spatial and temporal dimension, smaller and faster sensors are necessary. Thus, special microthermocouples have been developed for these experiments. The schematic set up of the MTCs which are embedded in the heater according to Fig. (2) is shown in Fig. (4). Each thermocouple consists of an insulated Constantan thermocouple wire fixed in the copper block by an electroplating process by which a copper layer of more than $500 \mu \mathrm{m}$ is added to the base of the heater (see Fig. (4)). Excess material is cut off afterwards and the resulting surface is prepared with emery paper P 4000. At this stage, the MTC wires are visible at the surface and their true positions can be measured with a microscope. The final step of preparation is coating of the surface in a DC-magnetron sputtering process. Three layers are used: a $2.5 \mu \mathrm{m}$ thick copper layer which serves as second conductor for the MTCs, then a $0.1 \mu \mathrm{m}$ thick titanium layer to prevent diffusion between the copper layer and the top layer and finally a $1.0 \mu \mathrm{m}$ thick pure gold layer against corrosion. Because sputtering preserves the mechanical features of the surface, the heating surface can be assumed to be prepared with emery paper P 4000 although it has never been in contact with emery paper at all.

The second conductor of the thermocouple is the sputtered copper layer on top of the heater preform (see Fig. (4)) which is contacted with insulated Copper thermocouple wires. The resulting thermocouple of type "T" has a circular shape of the sensitive area which is only little larger than the wire diameter itself. The Constantan wire diameters used here are $38 \mu \mathrm{m}$ and $50 \mu \mathrm{m}$, see Fig. 4 , the diameter of the Copper wires are $50 \mu \mathrm{m}$. The distance between the junction and the heater surface is given by the total thickness of the sputtered material $(3.6 \mu \mathrm{m})$ on top of the heater. 
According to the characteristics of the sputtering process and deposition rate calibration of the industrial-size facility, the thicknesses are known with high precision and thickness variations across the surface are negligible. This results in identical response characteristics for all thermocouples with the same wire diameter.

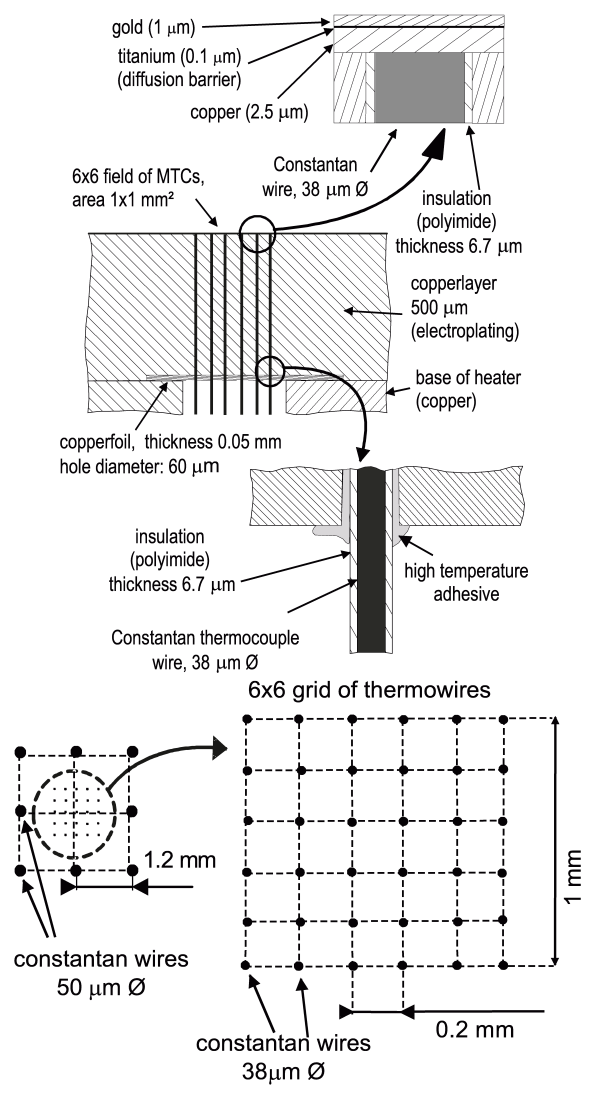

Figure 4. Setup of microthermocouples.

The preparation of the thermocouples is carried out as follows. First, the Constantan thermocouple wires $(38 \mu \mathrm{m}$ or $50 \mu \mathrm{m}$ conductor thickness, Polyimide insulation, $6.7 \mu \mathrm{m}$ and $5.7 \mu \mathrm{m}$ thick, respectively) are labeled for identification purposes. A thin copper foil is prepared with holes of approx. $60 \mu \mathrm{m}$ diameter, arranged in a rectangular grid of six rows with six holes each row, giving 36 holes in total. The spacing between the rows is $200 \mu \mathrm{m}$ so the total space spanned by the hole centers is $1 \mathrm{~mm}^{2}$. The $38 \mu \mathrm{m}$ Constantan wires are placed through these holes and then fixed with a high temperature adhesive. The foil with fitted Constantan wires is placed on the base of the heater and fixed with a high temperature adhesive (Epo-Tek 353 ND, Polytec Company). The Constantan wires run through a small hole to the side of the heater for electrical connection to the thermocouple amplifiers. At this point of preparation, 8 additional Constantan thermocouple wires with 50 $\mu \mathrm{m}$ diameter are mounted around the center grid manually under a microscope. The same procedure follows for 8 Copper wires which contact the copper layer after the sputtering process. The result of the described installation process is a six times six sensors array of fast response thermocouples on an area of $1 \mathrm{~mm}^{2}$ and an additional ring of 8 fast response thermocouples around this grid.

This method of preparation enables installation of miniature thermocouples very close to the heater surface without a local effect on surface characteristics like surface roughness or surface wettability, because the entire surface of the heater preform is prepared in an identical manner and afterwards uniformly coated by sputtering. Sputtering preserves the mechanical features of the surface roughness. In Buchholz et al., 2004, a 3-D topography measured above the microthermocouple grid shows no deformation of the surface above the tips of the MTCs. The same holds for chemical surface properties because the surface is evenly coated with a gold layer. However, one effect cannot be excluded: the local change of the thermal conductivity due to different materials (thermocouple, insulation, copper) could have an effect on the boiling process. The local temperature distortion as a measure for this effect was minimized during the design process using a simulation study of different designs of the MTC-array with various spacing of the MTCs and various thicknesses of the sputtered layers.

\section{Data Acquisition of Microthermocouple Experiments}

Acquisition of temperature fluctuation signals is realized as follows. The copper layer is connected to a single reference junction kept at $0^{\circ} \mathrm{C}$ via the copper wires. Each constantan thermocouple wire is connected to a very low noise instrumentation amplifier $(\mathrm{G}=$ 700). The output is filtered using a 4th order lowpass filter with a cutoff frequency of $7.5 \mathrm{kHz}$. The conditioned signals are sampled with two ADC-64 data acquisition boards for PC. These data acquisition boards are installed in two separate PCs because of the large data streams. Groups of 8 channels are sampled simultaneously. A special software allows burst-mode operation to minimize the time lag between channel groups 1-8, 9-16, 17-24 and 25-32. At moderate sampling rates, MTC data can be assumed to be measured simultaneously. Both data ADC-64 cards are synchronized with a main data acquisition system by digital signals using two DaqBoard 2000 multifunction cards, each with 16 input channels at 16 Bit (IOtech company) installed in a third PC. A sampling rate of $25 \mathrm{kHz}$ per MTC is used for the measurements.

\section{Micro Optical Probes (MOPs)}

Two phase flows associated with boiling exhibit a wide range of parameters such as void fraction, contact frequency and bubble diameter. For example, the local void fraction can be close to zero at the onset of boiling and one in film boiling at a position very close the the heater surface, see Hohl et al., 1998. Micro optical probes provide access to these parameters. They are well known for local measurements of liquid-vapor two phase flows. They are also known for the high accuracy of the measurements, see Arosio et al., 1999. In the past, most optical probes have been used in two phase flows with relatively large bubble diameters and large axial distances between the probe and a wall. In this type of flow, the disturbance caused by the probe with a standard tip diameter is not critical. The tip diameters of probes published in the literature are typically in the range between $10 \mu \mathrm{m}$ and $150 \mu \mathrm{m}$. In pool boiling, however, the situation is different. First, measurements with very small distances to the heater surface should be possible without significant disturbance of the flow because the important process of interfacial area generation takes place at the heated wall. Thus, measurements should be realized very close to the heater surface. Second, bubble sizes in boiling of common boiling fluids refrigerants for example - are much smaller than in air-water or steam-water flow at atmospheric pressure. Therefore a miniaturized optical probe has been developed.

\section{MOPs for FC-72 Experiments}

In the FC-72 experiments one single probe was used. It consists of a gradient index glass fiber with the end of the fiber formed into a conical shape. This was done by melting the tip under a microscope 
with a small burner. The fiber was then glued into small stainless steel tubes with increasing diameter to make it sufficiently stiff. The probe tip diameter is only $10 \mu \mathrm{m}$. The probe can be moved at different heights and different locations above the heater by means of a 3D-micrometer adjusting device. More details of this technique are presented by Hohl, 1999.

\section{MOPs for Isopropanol Experiments}

Recently Buchholz et al., 2004, developed improved optical probes which were used in experiments with isopropanol. The probes are made from single mode quartz glass fiber with a cladding diameter of $125 \mu \mathrm{m}$ and a core diameter of $8 \mu \mathrm{m}$. The tip of the probe is formed by etching in hydrofluoric acid. This method enables the preparation of very small probe tips. Measurements with a scanning electron microscope shows a tip diameter of less than 1.5 $\mu$ m (Fig. (5))
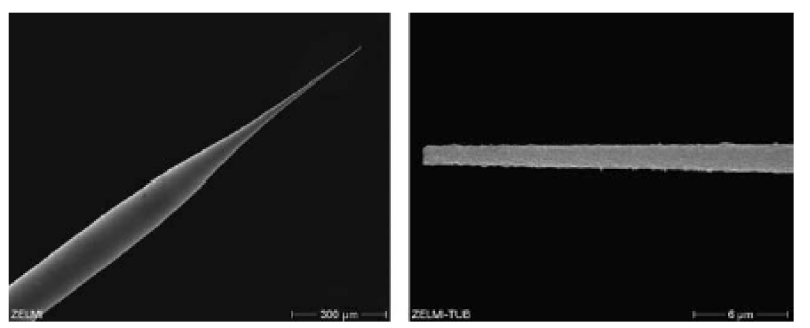

Figure 5. Scanning electron microscope photograph of the optical probe.

The probe is operated by an electronic detection unit. The main part is a bidirectional optical unit Bidi ${ }^{\circledR}$ (Infineon AG) which contains all necessary parts: a laser diode, a beam splitter and a PINphotodiode in a single device. The detection unit contains also electronics for safe operation of the laser diode and amplification of the detected signal. More details of the probe setup can be found in Buchholz and Auracher, 2002.

The position of the probe can be set in $\mathrm{x}-\mathrm{y}-\mathrm{z}$ direction with micrometer stages equipped with micrometer screws. The position perpendicular to the test heater -- the Z-axis - is measured both with the precision stage and at the same time with a precision LVDTdisplacement sensor. The accuracy of the sensor is $\pm 1.1 \mu \mathrm{m}$.

The optical probe system has been validated for the case of a twin optical probe with an axial probe distance of $425 \mu \mathrm{m}$ with a droplet impingement experiment. These tests prove low measurement error less than $\pm 5 \%$. This measurement error is mainly given by the the optical and temporal resolution of the test setup itself. For the validation experiment, a high speed video camera (Speedcam Pro, Weinberger AG) at 2000 fps and a high speed synchronized flash illumination (Speedflash, Weinberger AG) was used. The real measurement error is most likely well better than this conservative estimate from the validation experiments. The tests also show that the probe has an influence on the shape of the droplet interface. Fortunately, this deformation does not affect the accuracy of interface detection because the detection takes place prior to a visible deformation. This fact is most likely a result of the very small tip diameter - the small tip detects the interface and then the interface is being deformed at the larger fiber diameter above the tip. More details of the probe validation can be found in Buchholz and Aurecher, 2002.

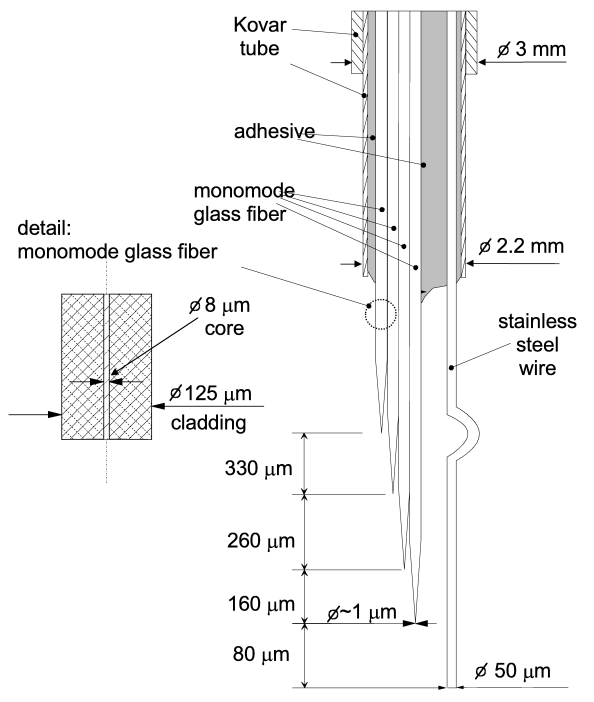

Figure 6. Setup of 4-tip optical probe.

Four of these optical probes have been combined to form a 4-tip optical probe, see Fig. (6). The optical fibers are placed next to each other with different axial distances. A stainless steel wire with 50 $\mu \mathrm{m}$ diameter for distance calibration is installed with about $800 \mu \mathrm{m}$ radial distance to the lower probe. The wire allows the calibration of the probe position by detecting an electrical contact between the wire and the heater surface. All positions, including the detection wires, have been set to the desired positions with precision micrometer stages and controlled with a calibrated microscope measurement system. The realized distances are indicated in Fig. (6). Although the distance between the lowest probe and the detection wire is $80 \mu \mathrm{m}$, the minimum probe distance is not limited to this value. Measurements very close to the heater surface are possible because the stainless steel wire has been coiled to form a 1winding spring. This spring allows the probe to be moved very close to the surface without a permanent change of the detection wire position or an effect on the optical probes.

The radial distance between any two probes which are next to each other in axial direction, is given by the fiber diameter and therefore $125 \mu \mathrm{m}$. The distance to the detection wire was chosen to be larger to minimize possible effects of the wire on the measured two-phase flow structure. The radial distance is approx. $800 \mu \mathrm{m}$.

All optical fibers and the stainless steel wire are glued together with a high temperature adhesive. The probe array is sealed with the same high temperature adhesive into Kovar tubes (low coefficient of thermal expansion) of different diameter to achieve minimum flow disturbance and sufficient stiffness of the probe. The Kovar tubes are gold plated from the outside to maintain test fluid purity.

The distance between the 4-tip optical probe and the heater surface is calibrated using the stainless steel wire. The calibration is carried out under low heat flux boiling condition. For the distance calibration, the probe is moved towards the surface very slowly. At the first electrical contact between wire and the heater the distance is $80 \mu \mathrm{m}$, because the wire has been set to this position during probe preparation. The reading of both the micrometer screw and the LVDT distance sensor are saved. For the experiments, all distances up to $1.5 \mathrm{~mm}$ distance are set using the LVDT reading, larger distances with the micrometer screw reading. At the lowest measured distance $(8 \mu \mathrm{m})$, an additional distance control was made. This is possible, because the probe signal increases if the probe is located closer to the heater than $8 \mu \mathrm{m}$. This effect is caused by a reflection of the emitted infrared laser light at the heater surface. At 
least a part of the reflected light is detected by the probe electronics. For the distance check during an experiment, the probe located at 8 $\mu \mathrm{m}$ is moved very slowly towards the surface with simultaneous measurement of the low signal level with a DPO oscillograph. At about $6 \mu \mathrm{m}$ probe distance, a level increase was detected. This test was performed for boiling setpoints between nucleate boiling and film boiling with identical results. The total distance error is therefore expected to be less than $\pm 2 \mu \mathrm{m}$ for distances up to $1.5 \mathrm{~mm}$ and less than $\pm 10 \mu \mathrm{m}$ for larger distances.

\section{Data Acquisition for Optical Probe Measurements}

For measurements with optical probes, one ADC-64 card is used with $200 \mathrm{kHz}$ sampling rate per channel. The duration of all test runs is 60 seconds. This duration is selected because of two reasons. First, the file size of up to one-minute runs at $200 \mathrm{kHz}$ (about 800 MB ASCII-data for $60 \mathrm{~s}$ ) permits later analysis without large numerical difficulties. Second, limited disk storage space would imply a reduced number of measured positions and / or temperatures along the boiling curve using longer test durations.

\section{Microthermocouple Probe (MTCP)}

Several attempts have been made to study the temperature field in boiling processes by small thermocouples (TC). A detailed discussion is presented in Buchholz, 2005. All these temperature sensors have some drawbacks due to their construction and/or their dimensions. Standard temperature sensors such as sheathed TCs are too large and also too slow to enable local measurements with acceptable temporal and spatial resolution. Commercial fine wire TCs can provide more localized measurements and faster response times. Unfortunately, additional sources of error are introduced because of their mechanical construction. Such TCs usually consist of two separate wires, roughly parallel to each other and connected at the active junction by some technique. A phase change from the liquid to the vapor phase can cause a liquid film to fill the gap between the wires. As the surface temperature of this film can be assumed to be at saturation temperature, an error is introduced as long as the liquid film is present. Experiments with a high speed video camera using droplets impinging on such TCs in the authors' lab have validated this conjectured effect. Consequently, the sensor should exclude this kind of effect by using a stretched setup or one wire instead of two. The stretched type on the other hand is not considered here as bubbles "tend to avoid the hot junction by rolling around the (horizontal) wire" (Delhaye et al., 1972). Thus, the TC should have a needle shape.

The construction of such an one wire TC means that deposition techniques need to be used in order to create the second conductor of the TC. For a fast response time of the TC, a thin wire is desirable. Flattening of the junction by any means (Beckman et al., 1993; Beckman, 1995) is not considered to be useful as the size of the junction is strongly increased. Consequently local measurements - especially very close to the wall - are no longer possible.

Our microthermocouple probe (MTCP) is designed according to the considerations above (Fig. (7)). A thin insulated constantan TC wire with a conductor diameter of $12.7 \mu \mathrm{m}$ and a polyimide isolation thickness of $1.3 \mu \mathrm{m}$ is connected to a constantan wire with a diameter of $50 \mu \mathrm{m}$ (Fig. (7)) in order to provide low electric resistance as this reduces electrical noise later during the measurements. A thin bare gold wire is placed about $2 \mathrm{~mm}$ behind the end of the thin wire and fixed with very little high temperature adhesive. In the next step a thin pure gold layer is added by vapor deposition to connect the gold wire and the cross-sectional area of the constantan wire at the tip of the MTCP. Afterwards, electroplating is used to increase the thickness of the gold layer. The thickness of the gold layer at the junction is estimated to be about 1 $\mu \mathrm{m}$. The location of the junction is therefore known with high precision. The characteristics of a gold-constantan TC is very close to a standard type $\mathrm{T}$ (copper-constantan) TC. It enables the use of standard components for reference junction and cabling. Details are given in the following paragraph.

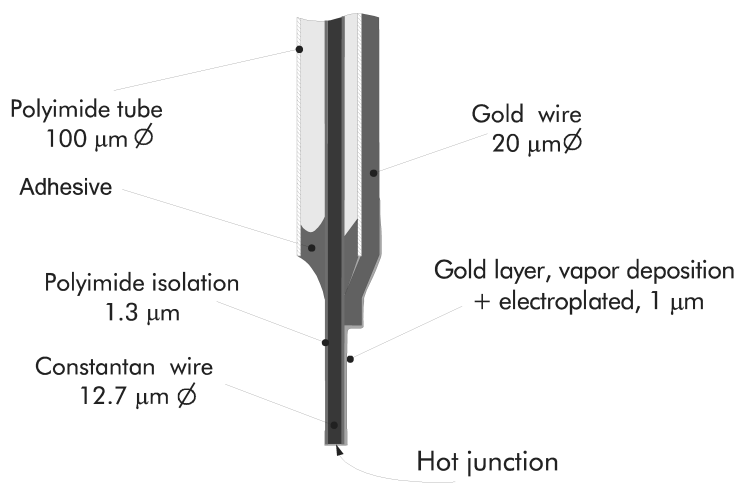

Figure 7. Setup of microthermocouple probe.

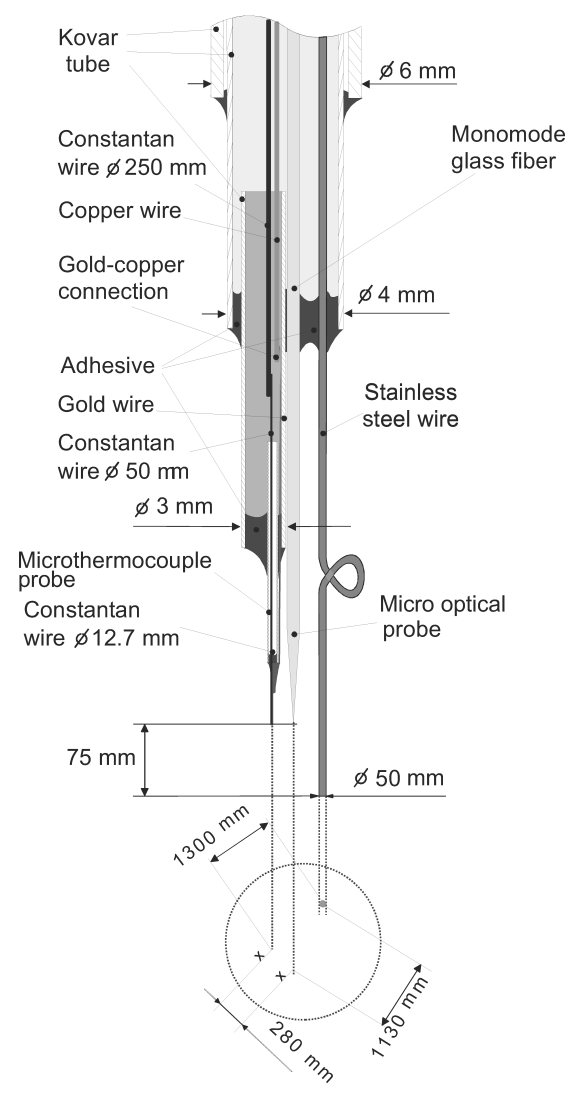

Figure 8. Setup of combined MTCP-MOP probe.

Inside the probe support tube (see Fig. (6), the gold wire is connected to a copper TC wire in order to enable usage of standard $\mathrm{TC}$ wires of type $\mathrm{T}$ and also a standard type $\mathrm{T}$ reference junction. The gold-copper connection introduces an additional gold-copper thermocouple in the electrical loop which can affect measurement accuracy although the relative EMF of copper and gold are quite similar. 
In order to access the potentially resulting measurement error, the characteristics of this material combination were investigated. For this purpose, a gold-copper TC was placed in a constant temperature calibration bath and connected with a gold-copper reference TC kept at $0^{\circ}$. Measurements were carried out between $20^{\circ}$ and $140^{\circ}$. Not surprisingly, the measured output voltage was less than $1 \%$ of the standard type T TC throughout the entire temperature range. For our purposes, this error does not result in a relevant measurement error, because the gold-copper junction is located inside the probe support tube ( $3 \mathrm{~mm}$ diameter, see Fig. (8)). There, the temperature corresponds to the fluid saturation temperature. It is fairly constant, since fluctuations possibly induced by the boiling two-phase flow are damped out due to relatively large tube mass and the thermal decoupling of the junction. Because of this construction, we get only a differential error as the constant TC voltage representing saturation temperature is still generated in the copper and constantan connection wires thus representing TC type $\mathrm{T}$ characteristics. The remaining error is compensated by a calibration curve which is deduced using the overall calibration curve and the gold-copper calibration curve.

The standard $63 \%$ response time $\tau_{63 \mathrm{MTCP}}$ of the MTCP was investigated prior to the pool boiling experiments using droplet impingement experiments. For a test run, a free falling droplet (about $50 \mathrm{~mm}$ free travel) of about $1 \mathrm{~mm}$ diameter impinged on the probe. An analysis of both, the MTCP signal and high speed video frames were used to determine $\tau_{63 \mathrm{MTCP}}$. In the experiments, $\tau_{63 \mathrm{MTCP}}$ can only be determined for a gas to liquid phase change. Four fluids were tested. We found response times of $0.15 \mathrm{~ms}$ for water, $0.24 \mathrm{~ms}$ for acetone, $0.27 \mathrm{~ms}$ for isopropanol and $0.36 \mathrm{~ms}$ for FC-72. However, the true $\tau_{63 \mathrm{MTCP}}$ values for the boiling experiment $\mathrm{s}$ may deviate from these data, because the conditions - especially fluid velocity and level of turbulence - are expected to be different from those during the impingement experiments. Taking the highly agitated and turbulent two-phase layer above the surface into account, the response may be faster during the boiling experiments.

\section{Data Acquisition of Microthermocouple Probe Measurements}

The MTCP voltage is amplified using a special very low noise amplifier $(G=700)$. The signal is filtered with a 4 th order lowpass with a cutoff frequency of $12.5 \mathrm{kHz}$. The signals are sampled with one ADC-64 card at $200 \mathrm{kHz}$. This high sampling rate is not necessary for proper acquisition of the MTCP signals but is needed because of the simultaneous measurement of the signals of an optical probe which is located next to the MTCP (see next chapter). The response time of the MOP is much faster than the MTCP thus a high sampling rate enables measurements with higher accuracy.

\section{Combined Microthermocouple and Optical Probe}

For measurements in the two-phase layer above the heater, a combined probe consisting of a MTCP and a micro optical probe (MOP) was manufactured. The schematic setup of the combined probe is depicted in Fig. (8). A stainless steel wire of a diameter of $50 \mu \mathrm{m}$ with about $1 \mathrm{~mm}$ radial distance to the active probes is used for distance calibration purposes. The combination of both probe types is important for the interpretation of the MTCP probe signals. The state of phase at the MTCP tip cannot be derived directly from the temperature signal since we have little a priori knowledge on the temperature characteristics. Although the MOP is located with some radial distance from the MTCP to prevent liquid film buildup between MOP and MTCP, the simultaneously measured MOP data provides a valuable guidance for the interpretation of the measured temperature data and allows separation of liquid and vapor temperature.

\section{Results of Boiling Curve Measurements}

\author{
Steady-State Pool Boiling Experiments With FC-72, Water \\ and Isopropanol
}

\section{FC-72}

Fig. (9) shows a boiling curve of FC-72 measured with heater no. 1 under steady-state conditions. The test fluid was saturated at $333 \mathrm{~K}$ corresponding to a pressure ratio of $\mathrm{p} / \mathrm{p}_{c r}=0.071$ (critical pressure $\mathrm{p}_{\mathrm{cr}}=1.83 \mathrm{MPa}$ ). The experiments were carried out with stepwise increasing and decreasing heater temperature. In contrast to Witte and Lienhard, 1982, postulation, no hysteresis was observed in the transition region. However, it should be mentioned, that in agreement with Ungar and Richhorn, 1996\}, observation, contamination during the steady-state experiments can shift the boiling curve. This was the case in preliminary experiments prior to the final cleaning of our test apparatus.

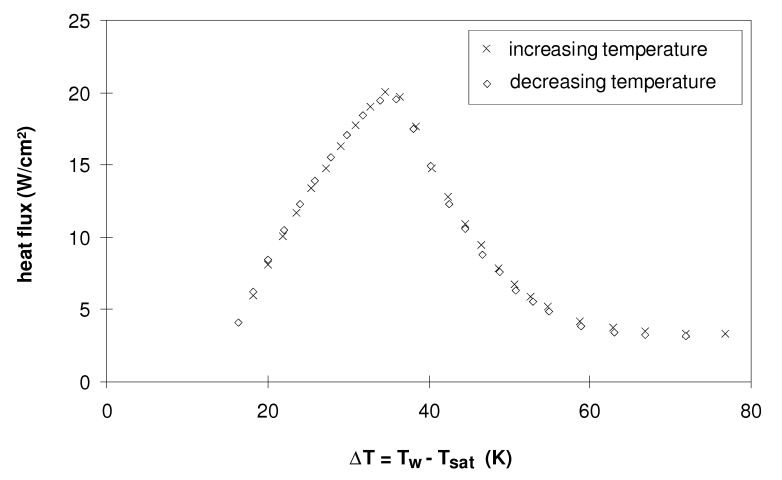

Figure 9. Steady-state boiling curve of FC-72 $\left(p=0.13 \mathrm{MPa} ; \mathrm{p} / \mathrm{p}_{\mathrm{cr}}=0.071\right.$ more details in Hohl, 1999

Some authors assumed that the results from our small heater are not representative because of the similarity of the heater diameter and the most dangerous Taylor wavelength. This is, however, not likely since the diameter of heater no. 1 is 4.3 times larger than this wavelength $\left(7.9 \mathrm{~mm}\right.$ for $\mathrm{FC}-72$ at $\left.60^{\circ}\right)$. It was furthermore mentioned that a hysteresis is not observed because of the small contact angle between FC-72 and nickel. For clarification we carried out experiments with water, where the contact angle is significantly larger than with FC-72.

\section{Water}

The experiments were performed at atmospheric pressure $\left(\mathrm{p} / \mathrm{p}_{c r}\right.$ $=0.0045$ ) with distilled water. It was carefully cleaned and degassed and several preliminary runs to clean the inner surfaces of the test loop have been carried out prior to the final experiments. A typical result is shown in Fig.(10). This boiling curve was measured with stepwise decreasing temperature from a starting point in the film boiling regime to low heat flux nucleate boiling. Afterwards, the heater temperature was increased stepwise starting in nucleate boiling until film boiling was reached again. The heater temperature control was able to stabilize the boiling process in all boiling regimes. All points of the boiling curve were measured under steady-state conditions. 


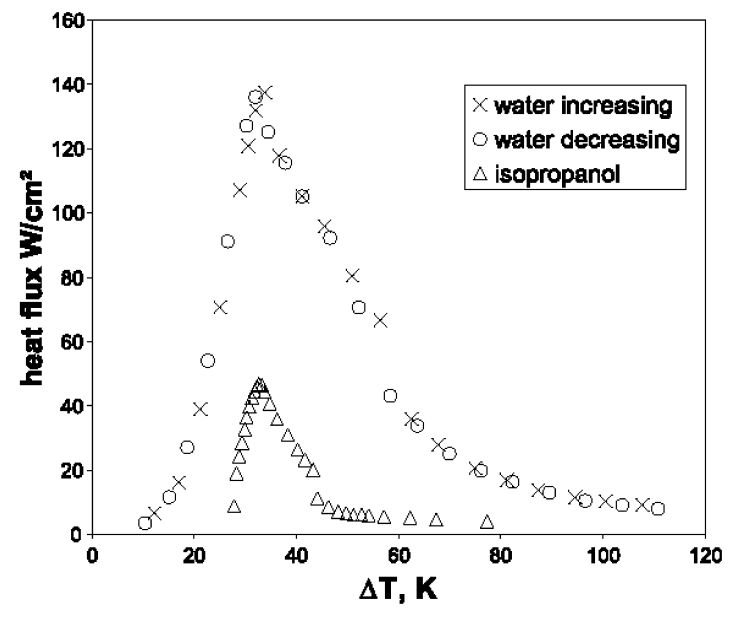

Figure 10. Steady-state boiling curve of distilled water $\left(\mathrm{p}=0.1 \mathrm{MPa} ; \mathrm{p} / \mathrm{p}_{c r}=\right.$ $0.0045)$ and isopropanol $\left(0.12 \mathrm{MPa}, \mathrm{p} / \mathrm{p}_{c r}=0.025\right\}$.

No distinct hysteresis in the transition boiling regime can be identified. However, a small disturbance in the shape of the otherwise smooth curve is recognizable at a $\Delta \mathrm{T}$ of about $55 \mathrm{~K}$ in Fig. (10). A similar but even smaller effect can be observed in the transition boiling region of isopropanol at $\Delta \mathrm{T} \approx 43 \mathrm{~K}$ (plotted also in Fig. 10\}). Our microthermocouples indicate that non-uniform boiling effects may cause these slight alterations of the boiling curve shape. Via the temperature distribution we indirectly observed larger clusters of dry patches on the surface which change their configuration with the wall superheat leading to the above mentioned disturbance. The size of the clusters is still smaller than the heater surface area but they are large enough to disturb the ergodic behavior of the boiling mode across the surface. In the measurements with FC-72 we did not observe this kind of disturbance. The effect is obviously the more pronounced the higher the heat flux is. Maybe also the contact angle, which increases from FC-72 via isopropanol to water, has an effect. We are not yet able to give a physical/mathematical explanation of this clustering effect in the transition region during steady-state experiments.

Fig. (11) shows boiling curves for power station feed-water on a surface with deposits. After approximately $30 \mathrm{~s}$ boiling at CHF to activate the nucleation sites on the heater and a subsequent decrease of the wall temperature, the heater temperature was increased stepwise from nucleate to film boiling and back vice versa. The shape of the boiling curve changed significantly during the experiment. Mostly, the boiling curve shifts to higher heat fluxes and the superheat at CHF decreases. The effect is similar to that one observed by Ungar and Eichhorn, 1996. During the measurement the boiling surface changed remarkably. An opaque layer of a white, hard substance built up on the heater. The disturbance of the boiling curve shown in Fig. (11) is not a result of insufficient reproducibility caused by the experimental facility itself, it is obviously a result of the continuously growing deposit on the surface. Reducing all possibilities which may lead to deposits to a minimum, e.g. insufficient purity of the test liquid, long measurement duration, insufficient cleaning of the boiling vessel and other parts of the loop in contact with the test fluid etc., leads to reproducible boiling curves as plotted in Fig. (10). On the other hand our experience is, especially with water, that boiling curves are very sensitive to contamination of the boiling surface in terms of reproducibility.

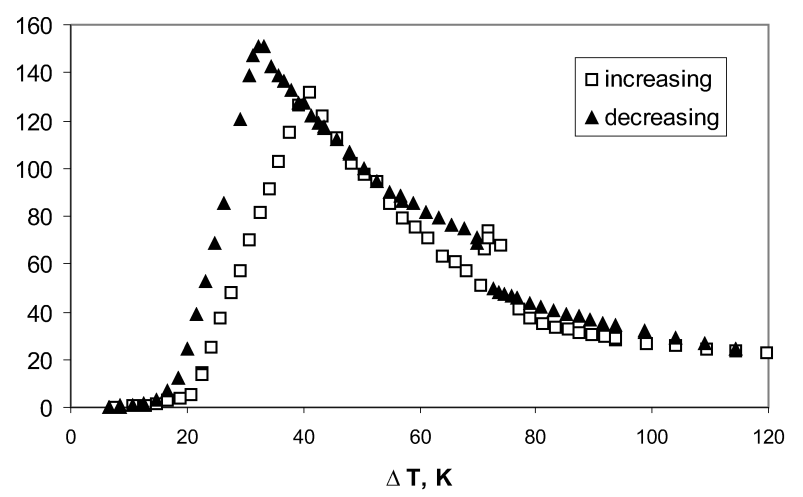

Figure 11. Boiling curves of power station feedwater on a surface with deposits at $0.1 \mathrm{MPa}\left(\mathrm{p} / \mathrm{p}_{c r}=\mathbf{0 . 0 0 4 5}\right)$. More details in Buchholz et al., 2000

Incidentally there is no indication that the above mentioned contamination effect is in any connection to the dry spot clustering effect in the transition region mentioned in the previous paragraph. It is also unlikely that this clustering effect is caused by insufficient controlling. In this case we would have either harmonic oscillations of the average surface temperature or a transition of this temperature to a stable operating point on the boiling curve (more details in Blum et al., 1996). Finally it should be mentioned that the most dangerous Taylor wavelength is $19 \mathrm{~mm}$ for boiling water at $0.1 \mathrm{MPa}$ and hence, as in the FC-72 experiments, much smaller than the heater diameter.

\section{Isopropanol}

The tests with isopropanol were carried out in a pressure range between $0.033 \mathrm{MPa}\left(\mathrm{p} / \mathrm{p}_{c r}=0.007\right)$ and $0.332 \mathrm{MPa}\left(\mathrm{p} / \mathrm{p}_{c r}=0.07\right)$. Hence, the system was-in contrast to the water experiments-closed to the atmosphere. As with the other fluids reproducible boiling curves could only be obtained with a carefully purified liquid and a clean surface. In this case again no hysteresis was observed between curves measured with stepwise increasing and stepwise decreasing temperature, respectively. An example is plotted in Fig. (10).

\section{Transient Pool Boiling Experiments With FC-72}

\section{Boiling Curves for Transient Heating}

Boiling curves for transient heating with up to $50 \mathrm{~K} / \mathrm{s}$ nominal temperature change per second of the heating surface measured with heater 2 (Fig. (2)) are depicted in Fig. (12). These curves represent heat fluxes and temperatures at the heater surface determined by solving the inverse heat conduction problem. For comparison, the steady-state boiling curve is also measured with stepwise increasing and decreasing temperature and again no hysteresis was observed. This curve deviates a little from the one in Fig. (9). The main reason is that we did not take into account precisely the heat losses of the different heaters. Consequently, some small errors are also included in the determination of the surface temperature. Since these errors have no influence on the qualitative shape of the boiling curves, we made no further correction of the plotted data. All experiments were carried out in a way that nucleation sites were already active at the start of heating $(\Delta \mathrm{T} \approx 15 \mathrm{~K})$ to avoid the disturbance effect of boiling incipience. 

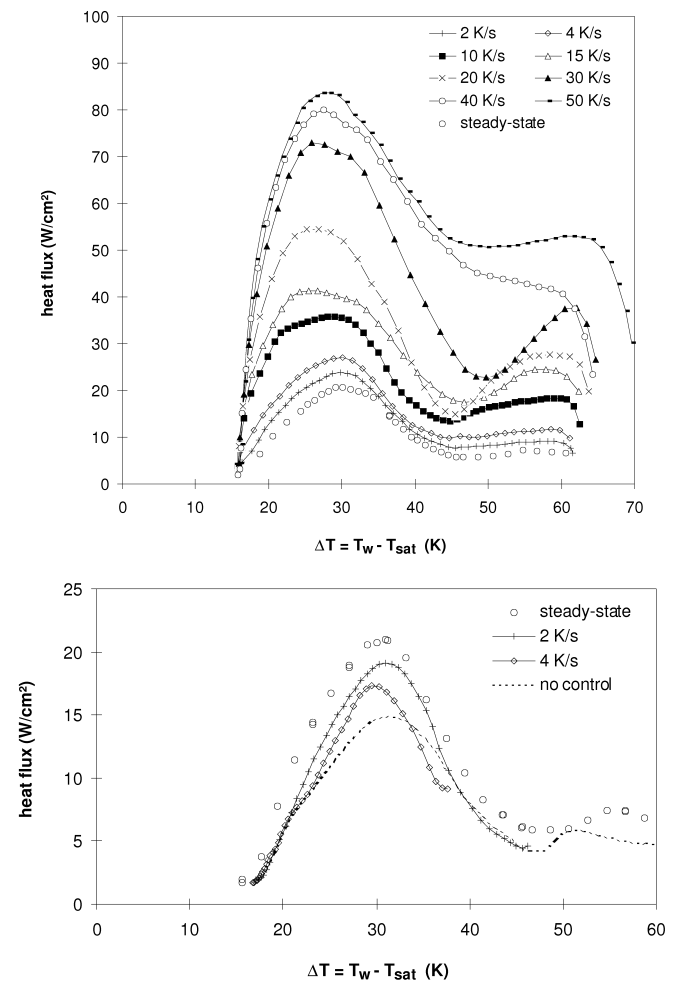

Figure 12. Boiling curves of FC-72 for transient heating, left, and transien cooling, right, at $0.13 \mathrm{MPa}\left(\mathrm{p} / \mathrm{p}_{\mathrm{cr}}=0.071\right)$. More details in Hohl et al., 2001).

Details of the transient experiments are presented by lcite\{Hohl2001Heat\}. Summarizing, the following main results were obtained:

- The heat flux increases strongly with increasing heating rate. At $50 \mathrm{~K} / \mathrm{s}$, the critical heat flux (CHF) is by a factor 4 larger than the one in the steady-state case. The superheat at CHF does not change remarkably with the heating rate.

- The minimum heat flux of film boiling (MHF) does not exhibit a clear trend. The heat flux in film boiling during the heating mode is significantly higher than in steady-state heating. After switching off the heating power to start the cooling mode somewhere between a superheat of 60 and 70 $\mathrm{K}$ the heat flux drops down to at least the value of the steady-state case.

- The behavior shown in Fig.(12) is not due to an evaluation uncertainty or error. An energy balance reveals that the inverse heat conduction problem is solved properly. The boiling curve characteristic in transient heating shown in Fig. (12) is due to a physical effect of the boiling mechanism. This holds also for transient cooling (Fig. (12), right).

\section{Boiling Curves for Transient Cooling}

Due to the thermal inertia of the heater the cooling rate is limited. Constant cooling rates were only possible for $2 \mathrm{~K} / \mathrm{s}$ along the entire boiling curve and for $4 \mathrm{~K} / \mathrm{s}$ between transition and nucleate boiling (see Fig. (12) right)). With zero heat input, the cooling rate was about $2 \mathrm{~K} / \mathrm{s}$ in film boiling and $6.8 \mathrm{~K} / \mathrm{s}$ in the CHF region. Obviously, the transient cooling effect is contrary to the transient heating behavior (note that the steady-state curve in Fig.(12), right, is the same as the one in Fig. (12)left). The faster the cooling rate the smaller the heat flux. Keys to a physical explanation of the transient boiling mechanisms are data obtained from optical probes and microthermocouples presented in the following.

\section{Results of Microsensor Experiments}

\section{Experimental Conditions and Procedure}

Two sets of experiments are performed: one set using isopropanol and a second set using FC-3284 (identical with Fluid PF-5052, 3M Company) as test liquid. To guarantee a high purity of the test fluid, the entire amount necessary for the experiments is charged in vapor state and condensed inside the facility using the condenser on top of the boiling vessel (see Fig. 1). The test liquid is thoroughly degassed prior to every experiment by vigorous boiling on the test heater as well as on the tube coils inside the boiling vessel. The tube coils are heated to a high temperature during the degassing procedure. Throughout this procedure, inert gases are repeatedly removed at the top of the condenser using a vacuum pump. Afterwards, the temperature of the tube coils is reduced to a lower temperature slightly above saturation temperature of the test liquid.

A first set of experiments is performed with isopropanol at saturation conditions at a reduced pressure of $\mathrm{p} / \mathrm{p}_{c r}=0.022$ which corresponds to a pressure of $0.106 \mathrm{MPa}$ and a saturation temperature of $83.3^{\circ} \mathrm{C}$. The last test series with the MTCP/MOP probe has been carried out at different conditions. Because of a defective temperature controller in the recirculated bath which sets the fluid temperature inside the boiling vessel, the fluid during this test series is slightly subcooled by about $0.5 \mathrm{~K}$.

For the second set of experiments saturated FC-3284 is used as a test liquid, also at a pressure of $0.106 \mathrm{MPa}$. Unfortunately, the critical pressure of this fluid is not known, therefore we cannot report the reduced pressure. Some problems have also been encountered for the saturation temperature of this fluid. In the literature, a saturation temperature of $50.0^{\circ} \mathrm{C}$ at atmospheric pressure has been reported (Howard and Mudawar, 1999). Accurate measurements with thoroughly degassed FC-3284 report a much higher saturation temperature of $53.2^{\circ} \mathrm{C}$ at the same pressure (Gorenflo, 2003). As can be expected from thermodynamics, a noteworthy volume fraction of inert gases should have a significant effect on the saturation temperature. In fact, FC-3284 can dissolve high volume fractions of inert gases (54\% 3M Company, Specialty Materials Europo Division, 2003). Due to these problems for the evaluation of the experiments with FC-3284, we used the measured temperature inside the boiling vessel after the degassing procedure as saturation temperature as we believe this to be most appropriate and realistic. During evaluation of the saturation temperature, medium heat flux boiling was present both on the test heater and the tube coils inside the test heater.

All experiments are carried out at steady-state. To prepare for a test run, the heater temperature controller is set to a temperature for high heat flux transition boiling to activate possible nucleation sites in order to avoid hysteresis at boiling incipience. The heater temperature is afterwards set to the first point of a test run in nucleate boiling and the measurements are started after steady-state conditions of the test heater have been reached. Then the temperature is increased to the next set-point value etc. until heat transfer and MTC / MTCP / MOP - data at all desired heater temperatures have been measured along the entire boiling curve.

Three test series are presented in the following: 1.) measurements with MTCs along the entire boiling curve for both fluids, 2.) measurements with MOPs for both fluids and 3.) measurements with the combined MTCP-MOP probe for isopropanol. Both probe experiment series cover a range of probe positions and some points of the boiling curve (chap. (3)). For the 
MOP and MTCP-MOP test runs, data are taken for all different probe distances to the surface at a constant heater temperature. After the last measurement, the temperature setpoint is changed to the next value and again data for all selected probe distances are taken. The measurements are realized with stepwise increasing temperature between low superheat in nucleate boiling and high superheat in film boiling. Both the MOP and the combined MTCP-MOP are located above the center of the heater.

\section{Microthermocouple Experiments}

\section{Evaluation of MTC signals}

For the analysis of the MTC data a good signal to noise ratio is important. Although the setup of the measurement chain for MTC signals is optimized for best signal integrity, some noise can be found in the signal. Unlike standard temperature measurements, averaging or simple filtering techniques can not be applied as they would destroy the signal dynamics (see also Fig. (17)). To design the data preparation scheme, the signal characteristics are analyzed from measurements with a discharged boiling facility and therefore without boiling components in the signal. The typical raw signal has a base noise level of about $\pm 0.05 \mathrm{~K}$ and additional relatively rare spikes of up to $\pm 0.015 \mathrm{~K}$.

The analysis uncovers three main types of noise. Noise type $\mathbf{A}$ is random noise generated by the MTCs itself and by cables and the thermocouple amplifiers, to a minor part also by the data acquisition (very high frequency components). Noise type $\mathbf{B}$ is pickup of line noise and multiples, i.e. 50, $100,150 \mathrm{~Hz}$ and above. Type $\mathbf{C}$ noise are signal spikes caused by electrical interference between the data acquisition systems and line voltage transients. This type of noise has by far the largest signal amplitude of all noise types, but because of the very short and rare spikes the influence is weak.

Because of this fact, noise type $\mathbf{C}$ is not removed in order to preserve best signal integrity. Noise type $\mathbf{B}$ can be removed using digital stop band filters. Digital zero phase lag (forward-backward) filters are used to perform this task as they maintain correct signal timing. The filters are designed with narrow bandwidth for minimum effect on the signal, just to give a smooth PSD without peaks remaining at the filtered frequencies. Noise type $\mathbf{A}$ has an acceptable low amplitude. Therefore only a 6th order digital lowpass (also zero phase lag) with a cutoff frequency of $8 \mathrm{kHz}$ is used to remove the high frequency components caused by the data acquisition itself. The MTC signal does not contain meaningful high frequency components above the cutoff frequency because a hardware lowpass filter with $7.5 \mathrm{kHz}$ cutoff frequency is used during acquisition to avoid aliasing.

The data preparation is performed in the following order: line noise filtering, low pass filtering and finally conversion to temperatures.

\section{Temperature fluctuations at the heater surface}

Typical traces of the measured temperature at two neighboring microthermocouples (MTCs) are depicted in Figs. (13), (14), (15) and (16) for nucleate boiling, CHF, transition- and film boiling. Each figure depicts traces for isopropanol (top plot) and for FC3284 (bottom plot). The plotted signals represent the temperature inside the heater at a position $3.6 \mu \mathrm{m}$ below the heater surface. The measured temperature at the MTC location is very close to the real surface temperature with respect to value and dynamics which has been shown by a solution of the inverse heat conduction problem (Lüttich et al., 2005). The horizontal distance between the thermocouple junctions of the neighboring MTCs No. 7 and 8 of the MTC array is $211.6 \mu \mathrm{m}$ (see Fig. 4).
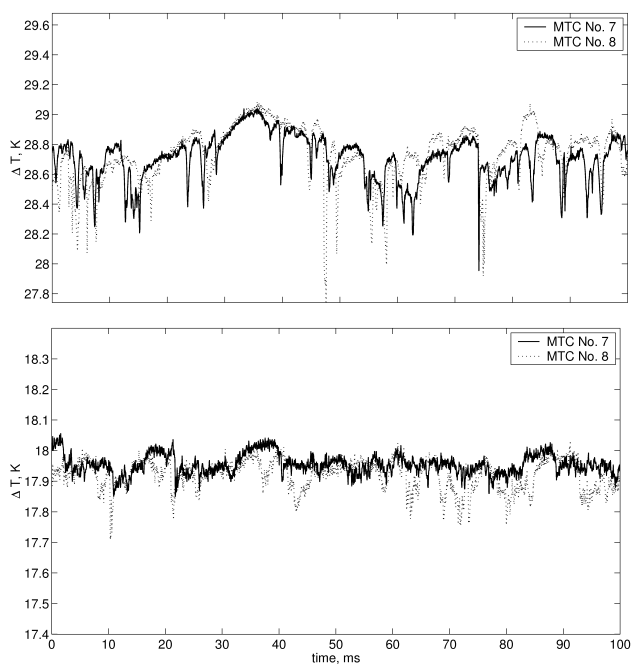

Figure 13. Temperatures at MTCs No. 7 and 8 in nucleate boiling; top: isopropanol, bottom: FC-3284. Horizontal distance $7 \rightarrow 8: 211.6 \mu \mathrm{m}$.
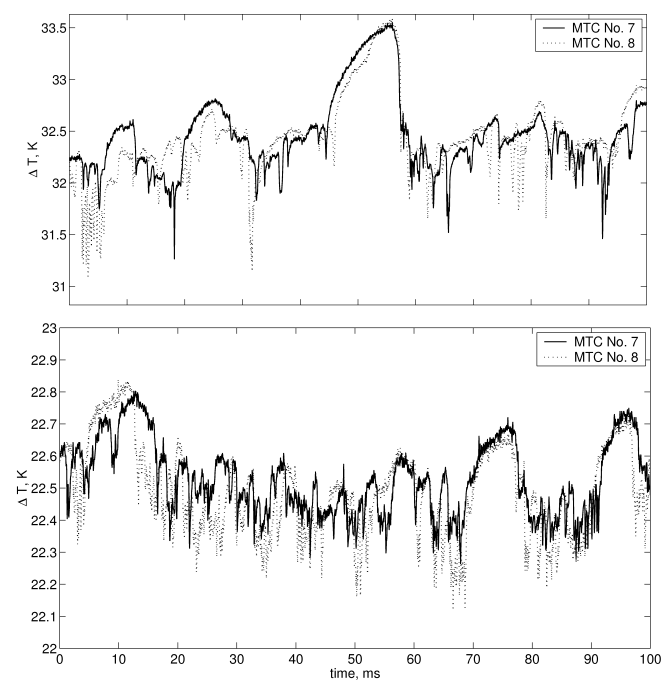

Figure 14. Temperatures at MTCs No. 7 and 8 at CHF; top: isopropanol, bottom: FC-3284. Horizontal distance $7 \rightarrow 8: 211.6 \mu \mathrm{m}$.
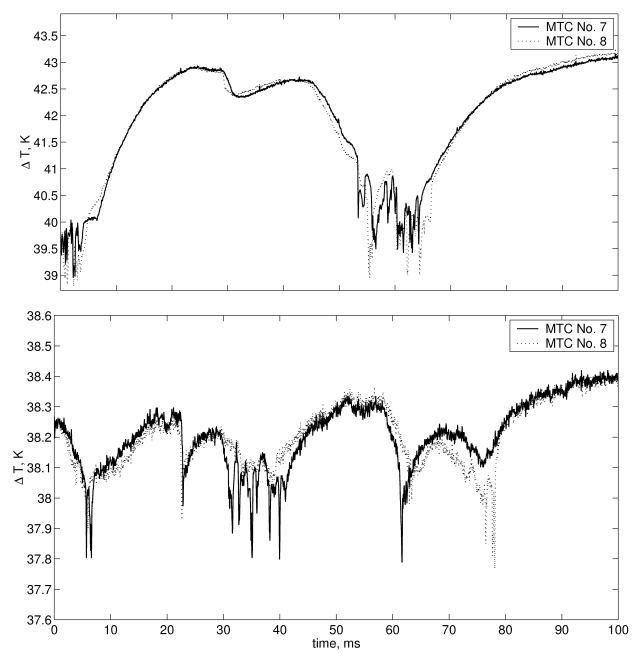

Figure 15. Temperatures at MTCs No. 7 and 8 in transition boiling; top: isopropanol, bottom: FC-3284. Horizontal distance $7 \rightarrow 8: 211.6 \mu \mathrm{m}$. 


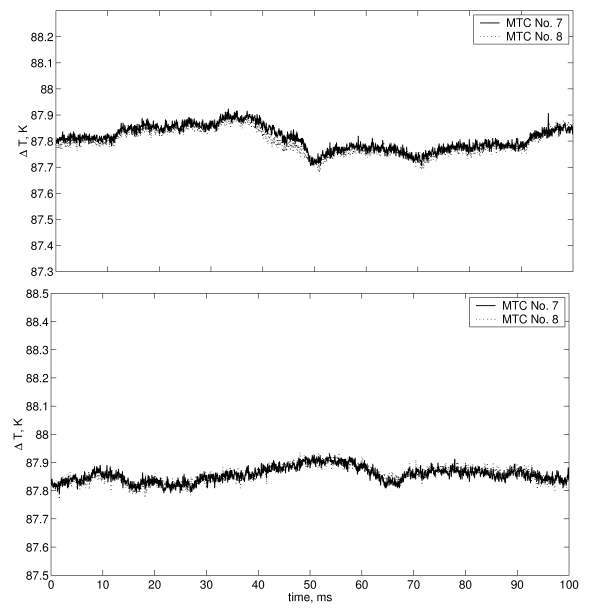

Figure 16. Temperatures at MTCs No. 7 and 8 in film boiling; top: isopropanol, bottom: FC-3284. Horizontal distance $7 \rightarrow 8: 211.6 \mu \mathrm{m}$.

The temperature traces in Figs. (13), (14), (15) and (16) are typical examples of the temperature dynamics, although a complete representation of the signal characteristics as well as its statistics for the vastly different time scales involved would require far more plots than possible here.

As can be expected, the amplitude of the temperature fluctuations measured with isopropanol increases with increasing wall superheat. This holds also for FC-3284, but at a generally smaller fluctuation amplitude. The latter is not very surprising since the measured mean heat flux is also smaller. The observed dependency of the fluctuation amplitude on the heater superheat can be expected because the theoretical limit for a temperature drop is (Tfluct $\max =$ Tsurface, $\max -$ Tsat for saturated boiling conditions Thus, the theoretical limit for a fluctuation amplitude increases with increasing superheat, except for film boiling where no wetting of the surface occurs.

The number of temperature fluctuations per time due to nucleation or a rewetting event changes also along the boiling curve. It increases between low heat flux nucleate boiling and around CHF. Increasing the wall superheat further leads to a decrease of the number of fluctuations until they vanish at the Leidenfrost point. Beyond the Leidenfrost point in the film boiling region, no comparably pronounced temperature drops can be found in the signal. Obviously, surface wetting does not take place beyond the Leidenfrost point. Assuming the ergodic hypothesis to be valid for our boiling system in this regime, no direct liquid contacts should occur on the entire heater surface.

Sharp temperature drops are detected in the region between low heat flux nucleate boiling and transition boiling close to the Leidenfrost point. A rapid temperature decrease points most likely to ongoing nucleation and subsequent growth of a bubble directly above or close to the MTC junction in nucleate boiling. In transition boiling, a temperature drop can be interpreted as local rewetting of the surface and subsequent nucleation and growth of small bubbles followed by a creation of larger vapor patches. The probability of a vapor patch to be present at the surface is commonly accepted to increase with increasing superheat from high to low heat flux transition boiling. The decreasing number of temperature fluctuations with increasing heater temperature in transition boiling fits with this understanding of transition boiling. Furthermore, also the results of optical probe measurements support this reasoning (see chapter (4.3)).

The local temperature transient at the MTC position during a rewetting period (transition boiling) can exceed $-30.000 \mathrm{~K} / \mathrm{s}$ for isopropanol. We compared the resulting temperature amplitudes (see Fig. (15)) with those which would be obtained if only unsteady heat conduction within the boiling liquid acted as a heat transfer mechanism during a rewetting event. If a vapor covered surface is wetted with saturated liquid, a contact temperature of $-0.67 \mathrm{~K}$ for isopropanol and $-0.36 \mathrm{~K}$ for FC-3284 below the surface temperature would be obtained $\mathrm{d}$ uring the contact if heat conduction between two semi-infinite bodies is assumed (assumptions: 1-D, saturated fluid, massive copper heater). Since observed temperature drops (see e.g. Fig (15)) are higher than these calculated values, unsteady conduction between liquid and heater cannot explain the measured temperature drops.

Furthermore, it is very unlikely that the temperature drops observed in transition boiling even near the Leidenfrost point are caused by local conduction through an extremely thin vapor film, i.e. without wetting of the surface which is sometimes postulated in the literature. This becomes obvious by a simple conservative estimate. We calculate the average local heat flux required to generate the temperature drops observed first. Then, we calculate the vapor film thickness needed to cause such heat flux by conduction only. The film would have a thickness of about $0.2 \mu \mathrm{m}$ to facilitate such a pronounced temperature drop. This thickness is less than the surface roughness of the heater $\left(\mathrm{P}_{\mathrm{t}}=0.88 \mu \mathrm{m}\right)$ and we do not believe that the film would not be pierced by the peaks on the surface.

Highly turbulent convection of liquid as explanation for the temperature drops along the boiling curve up to the Leidenfrost point can be excluded as this effect can certainly not cause such steep $\{$ lit and $\}$ localized temperature fluctuations. Thus, evaporation, i.e. the direct generation of vapor at the surface in the nearfield of the MTC, is likely to be the only realistic explanation.

This finding fits also with results gained from a theoretical analysis in Stephan and Hammer, 1994, where the processes are investigated which take place if bubbles grow at a heated wall at nucleate boiling. Stephan and Hammer, 1994, found a localized zone at the bubble foot - the so-called micro region - with extremely high heat fluxes. More recently, this finding was confirmed also experimentally using a steady evaporating meniscus, see Höhmann and Stephan, 2002. It is likely, that evaporation in the micro region cause the pronounced temperature drops observed, the more as they are very local events. Even at the neighboring MTCs (distance 211.6 $\mu \mathrm{m})$ some fluctuations occur independently at both MTC junctions. These sharp temperature drops are mostly not well correlated. On the other hand, slower temperature changes - slow compared to the very rapid changes during nucleation or rewetting - are much better correlated at neighboring MTCs, see Fig. Fig. (14) and also Fig. (15). This finding points most likely to the existence of larger structures on the surface like dry patches in transition boiling.

Although the theory of micro region evaporation was developed for single bubbles, the principal findings are expected to describe also the fundamental processes at the three-phase contact line between the heated wall, liquid and vapor in all boiling regimes with surface wetting in general. This approach has been employed to model pool boiling along the entire boiling curve successfully by Lüttich et al., 2005 (see chap. 5.1).

Periods with high temperature in transition boiling are often simultaneously observed by far more than just two neighboring MTCs. A visualization of such an event (in this case close to CHF in nucleate boiling) can be found in Fig. 14 of Buchholz et al., 2004 (it is recommended to use the online version on www.sciencedirect.com to view the figure in color). Therefore, the area covered by such unstable vapor patches can be expected to be partly in excess of $1 \mathrm{~mm}^{2}$ at CHF, and even larger at higher wall superheats. If the patch is larger than $1 \mathrm{~mm}^{2}$ a real identification of the size is difficult, because they exceed the size of the MTC array. 
Within these dry patches the measured temperatures at neighboring MTCs can be expected to be similar because the thermal conduction within the heater is strong relative to the local surface heat flux. The same holds for areas without bubble nucleation in low heat flux nucleate boiling because natural convection certainly cannot cause localized pronounced temperature drops on a heater with high thermal conductivity and thermal capacity.

Some temperature traces in Figs. (13) to (16) show, as discussed above, fast temperature drops of more than $-3 \cdot 10^{4} \mathrm{~K} / \mathrm{s}$. To find out whether these measured temperature drops are biased by data evaluation a simulation has been carried out for reduced bandwidth during acquisition (Fig. 17). The measured signal (cutoff frequency $f_{c}=7500 \mathrm{~Hz}$ ) is compared to curves with reduced bandwidth. The additional curves are calculated using the same signal, but a digital zero-phase lag (for easier comparison) lowpass filter order 4 with the cutoff frequencies as given in Fig. 17. It is obvious that the chosen cutoff frequency yields a signal which is very near to the 'true' one whereas significant smaller $f_{c}$ 's underestimate the strong slope of the signal.

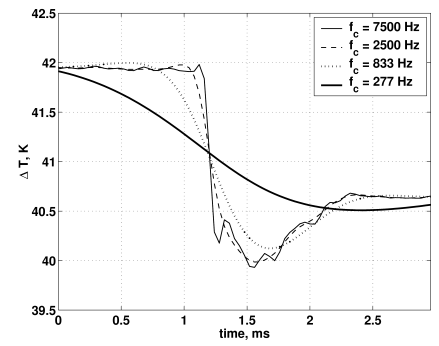

Figure 17. Effect of acquisition bandwidth on signal characteristics during a temperature drop.

\section{Micro Optical Probe Experiments}

\section{Evaluation of MOP Signals}

The signals of the optical probes basically contain a binary information: vapor or liquid phase at a given moment at the probe tip. This information can be represented with a Phase Indicator Function PIF:

$$
\operatorname{PIF}(\vec{x}, t)=\left\{\begin{array}{l}
1 \text { for vapor } \\
0 \text { for liquid }
\end{array}\right.
$$

To extract this binary information from the raw signal an analysis procedure is used. The PIF identification method is based on an algorithm developed by Hohl, 1999. It is optimized and adapted to the characteristics of the new optical probes.

The calculated PIFs are the data basis for all analysis of the two phase flow characteristics. The first step of the analysis towards the PIF is filtering of the raw signal to remove noise which is basically optical noise, most likely from the laser diode, its drive cirquits and the optical fiber itself. The denoising process is based on wavelets as this approach allows removal of noise at low and high signal levels while preserving the characteristic steep changes of the signal at fluid phase changes at the probe tip which are essential for precise detection of the phase changes. Although detection of the PIF without denoising of the raw probe signals is possible, denoising improves confidence of the following PIF detection process and allows usage of a faster detection algorithm than without denoising. The next step towards the PIF is calculation of the average signal levels representing liquid and vapor phase. These levels are used to limit the low signal level to the average liquid level and vice versa for the high signal level (vapor). The limiting of the signal to the average bounds avoids misinterpretation of signal overshoot at liquid to vapor transitions (for more information on overshoot see Buchholz and Auracher, 2002), For the decision if the signal at a point $i$ represents vapor or liquid, the detection algorithm calculates the differences between $i$ to $i-1+1, \ldots, i+\mathrm{N}$ with $\mathrm{N} \leq 4$. A phase change at point $i$ is identified, if there is a sufficient change between $i-1$ and $i$ or, if there is a smaller change between these points but the criteria is fulfilled for any of the calculated differences. An additional check for the signal level follows to permit also detection of very slow signal changes. Slow signal changes are very rare, but the check improves the confidence of the calculated PIF. The algorithm can be classified as a combination of an optimized differentiation method and the two-level method.

The average void fraction at a given probe location $z$ can be calculated from the PIF as

$$
\alpha_{v}(z)=\frac{1}{N} \sum_{i=1}^{N} \operatorname{PIF}(i, z)
$$

All average void fraction data points are calculated using a $60 \mathrm{~s}$ long data set (12 million data points).

As a first approach towards a mean interface velocity perpendicular to the heater surface, the cross-correlation function can be used. For this purpose, only the time lag at the maximum of the cross-correlation is of interest. Therefore, calculation of the entire function is not necessary. Numerical restrictions (large signal size) and desired accuracy force to use a direct calculation of the cross-correlation for the region of interest. After calculation of the cross correlation coefficient, the time at the peak maximum can be identified. The mean velocity of the interfaces can then be calculated as

$$
w_{m, i}(z) \frac{\Delta s_{i}}{\Delta t_{i}(z)}
$$

with $\Delta s_{i}$ the axial distance between the correlated probe pair $i=1 \ldots 3$ and $\Delta t_{i}(z)$ the identified time lag at probe position $z$ of the maximum of the cross-correlation coefficient. The cross correlation coefficient is presented as "a first approach" towards a mean interface velocity, because we believe that there are better options to calculate the velocity than using the cross correlation coefficient. The main reason is that the cross correlation coefficient analyzes the entire signal no matter what the underlying physics are. An adopted algorithm will be presented in the future.

\section{MOP Results for FC-72}

Experiments with FC-72 have been carried out with heater no. 1 and the probe with $10 \mu \mathrm{m}$ tip diameter under steady-state conditions. Details are presented by Hohl et al., 1998. Outcome of these measurements are e.g. void fractions and vapor contact frequencies as a function of the distance to the heater. A typical result for the void fraction distribution is plotted in Fig. (18).
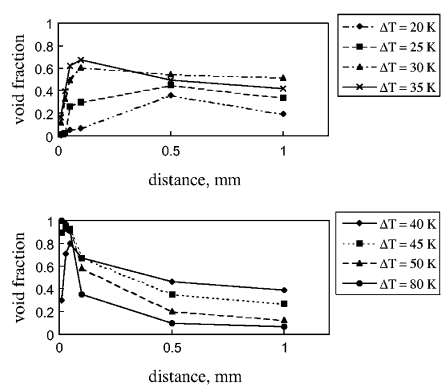

Figure 18. Time averaged void fraction of FC-72 above heater in different boiling regimes. 
Measurements were carried out at the center of the heater at distances of the probe tip from the heater surface between 0.01 and $1 \mathrm{~mm}$. The distance was determined with an accuracy of $\pm 0.01 \mathrm{~mm}$ by measuring the signal rise as a result of light reflection at the heater surface when the probe comes very close to it. In measurements at $0.01 \mathrm{~mm}$. nominal distance from the heater, it can be assured that the probe tip was fixed within a real distance between 0.005 and $0.02 \mathrm{~mm}$ from the heater surface.

The data in Fig. (18) indicate that in nucleate boiling up to CHF $(20 \mathrm{~K}<\Delta \mathrm{T}<35 \mathrm{~K}$, see Fig. (19)) the void fraction decreases sharply when the probe approaches the heater surface. This can also be observed at $\Delta \mathrm{T}=40 \mathrm{~K}$ in transition boiling. Then the liquid rich layer near the surface gradually disappears if film boiling is approached. The void fraction maximum above the heater is found to be at about $0.5 \mathrm{~mm}$ in nucleate boiling, at $0.1 \mathrm{~mm}$ at CHF, at 0.05 $\mathrm{mm}$ at $\Delta \mathrm{T}=40 \mathrm{~K}$ and it reaches the heater surface at about $\Delta \mathrm{T}=50$ $\mathrm{K}$. The void fractions at the surface in the $\Delta \mathrm{T}$ region below $50 \mathrm{~K}$ are remarkably small. If the data in Fig. (18) are extrapolated to the heater surface, which certainly implies some error, we observe, e.g. at CHF, a non-wetted fraction of less than about $15 \%$.

Hohl et al., 1998, presents also data for vapor contact frequencies at the probe tip. The number of vapor contacts increases when the probe is moved towards the heater surface and reaches frequencies as high as $500-600 \mathrm{~Hz}$ at about $0.05 \mathrm{~mm}$ from the heater surface. It seems that at about these distances the probe detects bubbles from several nucleation sites during their growing period. At larger distances the bubbles coalesce to bigger vapor masses resulting in a decrease of the frequency. A further approach of the probe tip to the surface results in a decrease of the frequency. An explanation could be that at these very small distances the probe tip touches less and less bubbles during their growing period probably at most two because the detected frequencies are less than $100 \mathrm{~Hz}$ at nominal tip distances of $0.01 \mathrm{~mm}$ to the surface.

In transient boiling the probe measurements were not successful due to the unavoidable thermal expansion and contraction of both the probe and the heater. It turned out that during a transient run the distance between the probe tip and the heater surface varied within a range where the strongest changes in contact frequencies and other quantities occur.

\section{MOP Results for Isopropanol}

Buchholz et al., 2004, carried out similar measurements as Hohl et al., 1998, with isopropanol along the boiling curve depicted in Fig. (10). He used the 4-tip probe described in chapter (2.6.2) (Fig. $6)$ ). esults for the void fraction distribution measured with the probe nearest to the surface (probe 1) in different boiling regimes are shown in Fig. (19). Fig. (20) presents a zoom into the plots of Fig. (19) for the heater nearfield region.

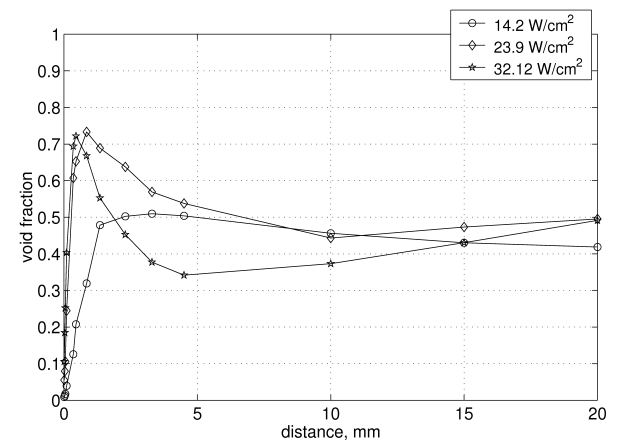

Figure 19. Mean void fraction of isopropanol for entire distance range to the surface, left: nucleate boiling, middle: nucleate boiling up to CHF, right: transition and film boiling.
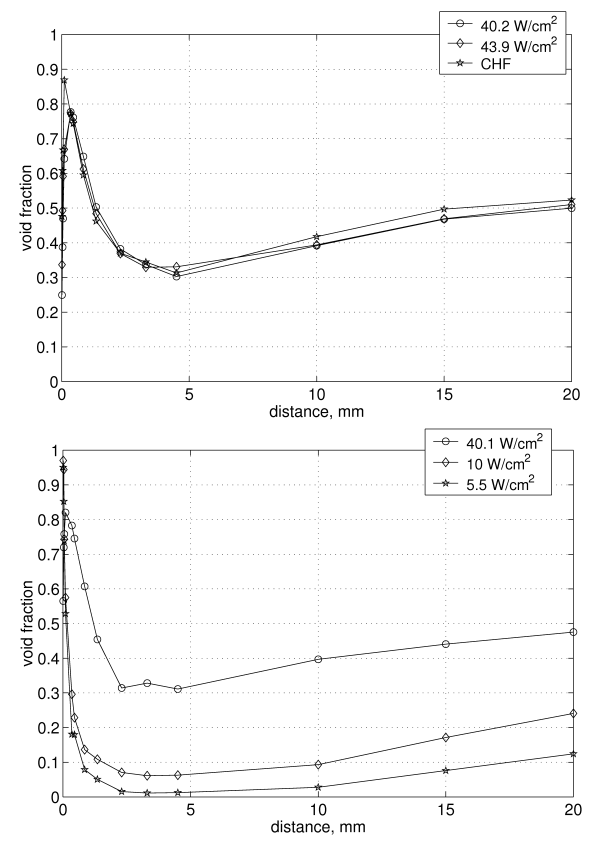

Figure 19. (Continued).
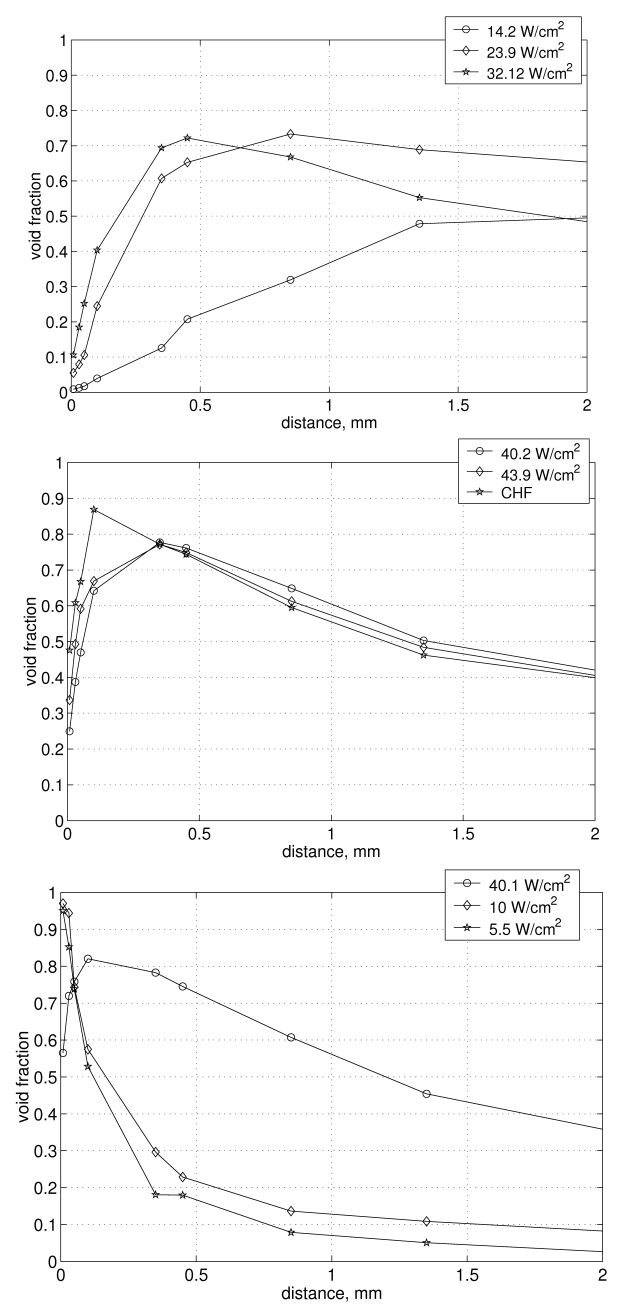

Figure 20. Mean void fraction of isopropanol for 0-2 $\mathrm{mm}$ distance to the surface, left: nucleate boiling, middle: nucleate boiling up to CHF, right: transition and film boiling.

\section{J. of the Braz. Soc. of Mech. Sci. \& Eng.}


The void fraction characteristics are very similar to the findings by Hohl et al, 1998 (Fig. (18)). A liquid rich layer very near to the surface is observed. The void fraction at the closest measured distance to the heater $(8 \mu \mathrm{m})$ increases monotonically from low superheats via CHF to film boiling. Even in transition boiling (40.1 $\mathrm{W} / \mathrm{cm}^{2}$ ) a decrease of void fraction towards the surface exists. A distinct local maximum of the void fraction distribution occurs in all boiling regimes between moderate nucleate boiling and transition boiling $\left(\sim 40.1 \mathrm{~W} / \mathrm{cm}^{2}\right)$. The distance between the location of the maximum and the heater surface becomes smaller with increasing wall superheat. It is about $0.85 \mathrm{~mm}$ at $23.9 \mathrm{~W} / \mathrm{cm}_{2}$ (nucleate boiling) and reaches about $0.1 \mathrm{~mm}$ in high heat flux transition boiling $\left(\sim 40.1 \mathrm{~W} / \mathrm{cm}^{2}\right)$. Not surprisingly the distances between the maxima and the surface are somewhat larger than in FC-72 boiling since most likely a relation exists between bubble departure diameter $d_{B}$ and void fraction maximum, and $d_{B}$ of isopropanol is larger than the one of FC-72 (see chap. (6.2)).

The void fraction curves exhibit a minimum at a distance of $\sim 4.5 \mathrm{~mm}$ between fully developed nucleate boiling and film boiling (Fig. (19). Moreover the void fraction at the largest measured distance $(20 \mathrm{~mm})$ is more or less constant $(\sim 0.5)$ between nucleate boiling and CHF. These findings are discussed in the

paragraphs on cross correlation later in this chapter. Until now the void fraction data has not been calculated for the other probes of Buchholz' et al.'s 4-tip sensor since huge computation time is required to obtain statistically correct results.

The 4-tip sensor offer the possibility to determine an average interphase velocity in the tip region by cross correlation of the different probe signals. One of the examples presented by Buchholz et al., 2004, is shown in Fig. (21). Here, the cross correlation coefficients for probe combinations $1 / 2,2 / 3$ and $3 / 4$ are plotted for two distances of the lower probe (1) to the surface: 4.5 and $20 \mathrm{~mm}$. Two characteristics are obvious: 1 . The larger the distance of the probe ensemble to the surface the better the correlation. In fact, Buchholz et al, 2004, report that very weak correlation coefficients are obtained at the smallest distance of $8 \mu \mathrm{m}$ of the lower probe to the surface. This may be an indication of increasing "disorder" of the two-phase layer towards the surface caused by bubble agitation. 2. The smaller the distance of subsequent probes the better the correlation (note: $1 \rightarrow 2,160 \mu \mathrm{m} ; 2 \rightarrow 3,260 \mu \mathrm{m} ; 3 \rightarrow 4,330 \mu \mathrm{m}$ ).

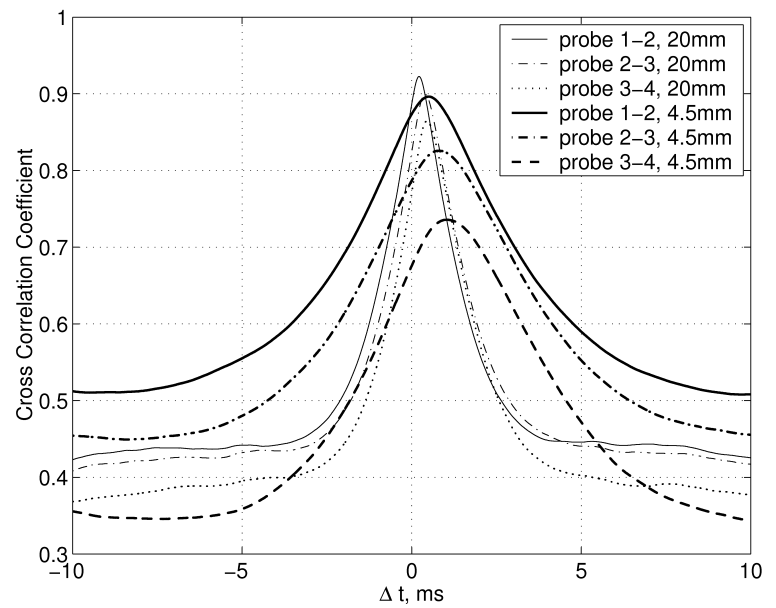

Figure 21. Cross correlation coefficients for $20 \mathrm{~mm}$ and $4.5 \mathrm{~mm}$ distance of the lower probe to heater surface. Nucleate boiling of isopropanol at $14.2 \mathrm{~W} / \mathrm{cm}^{2}$.
Table 1. nterface velocity between nucleate boiling and CHF at two probe positions. Isopropanol experiments.

\begin{tabular}{|c|c|c|c|}
\hline & Probe 1-2 & Probe 2-3 & Probe $3-4$ \\
\hline \multicolumn{4}{|c|}{ Distance between heater surface and lowest probe $4.5 \mathrm{~mm}$} \\
\hline$\dot{q}=14.2 \mathrm{~W} / \mathrm{cm}^{2}$ & $0.31 \mathrm{~m} / \mathrm{s}$ & $0.32 \mathrm{~m} / \mathrm{s}$ & $0.32 \mathrm{~m} / \mathrm{s}$ \\
\hline$\dot{q}=32.1 \mathrm{~W} / \mathrm{cm}^{2}$ & $0.53 \mathrm{~m} / \mathrm{s}$ & $0.58 \mathrm{~m} / \mathrm{s}$ & $0.56 \mathrm{~m} / \mathrm{s}$ \\
\hline $\mathrm{CHF}$ & $0.82 \mathrm{~m} / \mathrm{s}$ & $0.81 \mathrm{~m} / \mathrm{s}$ & $0.81 \mathrm{~m} / \mathrm{s}$ \\
\hline
\end{tabular}

\begin{tabular}{lccc}
\multicolumn{4}{c}{ Distance between heater surface and lowest probe $20 \mathrm{~mm}$} \\
$\dot{q}=14.2 \mathrm{~W} / \mathrm{cm}^{2}$ & $0.73 \mathrm{~m} / \mathrm{s}$ & $0.66 \mathrm{~m} / \mathrm{s}$ & $0.73 \mathrm{~m} / \mathrm{s}$ \\
$\dot{q}=32.1 \mathrm{~W} / \mathrm{cm}^{2}$ & $0.78 \mathrm{~m} / \mathrm{s}$ & $0.8 \mathrm{~m} / \mathrm{s}$ & $0.82 \mathrm{~m} / \mathrm{s}$ \\
$\mathrm{CHF}$ & $1 \mathrm{~m} / \mathrm{s}$ & $0.98 \mathrm{~m} / \mathrm{s}$ & $1.05 \mathrm{~m} / \mathrm{s}$ \\
\hline
\end{tabular}

The time differences at the peak maxima and the fixed distance between the tips yield an average interphase velocity at the different probe positions above the surface. The velocities are summarized in table(1) for the region between low superheat nucleate boiling (14.2 $\mathrm{W} / \mathrm{cm}^{2}$ and $\mathrm{CHF}$ ) for two distances above the heater.

These data is helpful for an interpretation of the void fraction profiles in Figs. (19) and (20). Looking at the profiles it is in the first glance surprising that the void fractions at both 4.5 and $20 \mathrm{~mm}$ distance are approximately equal between nucleate boiling (32.12 $\mathrm{W} / \mathrm{cm}^{2}$ ) and CHF though the heat flux and thus the generated mass flow of vapor increases. This is explainable if the velocity rises with increasing heat flux and in fact this trend is proved by the data in table (1). Furthermore we observe higher velocities at the larger distance $(20 \mathrm{~mm})$ and simultaneously an increase of void fraction between 4.5 and $20 \mathrm{~mm}$ at a given heat flux (Fig. (19)). It seems that the two-phase flow is accelerated in this section above the heater and that in addition a contraction of the bubbly flow area in upward direction occurs. Both effects would increase the measured velocity and also increase the void fraction in upward direction.

Buchholz et al., give no explanation for the strong decrease of void fraction at fixed heat fluxes after the maximum at least in the higher heat flux region. More detailed investigations are required using the huge amount of data available now to give an answer.

\section{Microthermocouple Probe Experiments}

\section{Evaluation of MTCP Signals}

MTCP probe signals are conditioned as follows. Typical discrete frequencies like line noise etc. are not present in the signal because of careful shielding and design of the electronics used. Even though the entire signal chain has been optimized to achieve an optimum signal to noise ratio, some noise can be found in the signal. The observed level of noise is partly the result of the signal bandwidth which is exceptionally large for temperature measurements. The thermal noise voltage $U_{\text {noise }}$, for example, can be calculated by $\mathrm{U}_{\text {noise }}=\sqrt{4 \mathrm{kTR} \Delta \mathrm{k}}$ with the Boltzmann constant $\mathrm{k}$, the temperature $\mathrm{T}$, the electric resistance $\mathrm{R}$ and the bandwidth $\Delta \mathrm{f}$ (Skritek, 1998). Common techniques like averaging or application of low-pass filters cannot be used here as the important signal dynamics will be altered (see Fig.17)).

These drawbacks can be overcome with the application of wavelets for signal denoising. As already mentioned, this method enables reduction of noise while preserving the characteristic signal features. The observed noise floor of the raw signal (measured in Kelvin peak-to-peak) after conversion to temperature is typically between about $\pm 0.04 \mathrm{~K}$ to $\pm 0.1, \mathrm{~K}$. Application of wavelet denoising results in a reduced noise level of about $\pm 0.01 \mathrm{~K}$ or less. The next step is the removal of outliers. These are very rare (most files do not 
have a single outlier) but would result in errors during the statistical analysis which will be presented in the future. Outliers are defined here as temperature peaks with values well beyond the range of temperatures possible from theory (i.e.well below $\mathrm{T}_{\text {sat }}$ or above $\mathrm{T}_{\text {heater }}$ ). After the mentioned signal conditioning, the signals are converted to temperatures.

For the mapping of the measured probe-temperatures to either the liquid or the vapor phase, the MOP provides valuable information on the state of phase at the probe tip. Due to the radial distance between the probes (see Fig.(8)) - which is necessary to avoid a liquid film between both probes - a phase change does not occur at the same moment at the MOP and the MTCP in general. The time deviation is a function of the bubble diameter, the flow properties (turbulence etc.) and the radial probe distance. It is expected to be minimal for large bubbles and low turbulence. Anyhow, the temperature traces presented in the following chapters enable a clear determination of the instances of phase change at the probe tip. Corresponding MOP and MTCP signals are not presented because the direct interpretation could be misleading for short signal periods as presented in the following.

Temperature traces measured with isopropanol are depicted in Fig.(22) for low heat flux nucleate boiling, in Fig.(23) for film boiling, in Fig.(24) for CHF and in Fig.(25) for transition boiling. Each figure depicts signals at a distance of $9 \mathrm{~mm}$ (left) and 0.1 $\mathrm{mm}$ (right) of the probe. Note that Figs.(22) and (23) depict time intervals of $400 \mathrm{~ms}$ and Figs.(24) and (25) of only $100 \mathrm{~ms}$. We selected these different durations for the sake of best representation of the short-term dynamics in these regions. The observed events occur on a relatively wide range of time and temperature scales and consequently the plots should not be considered to completely represent the entire boiling process.

\section{MTCP Results for Nucleate Boiling of Isopropanol}
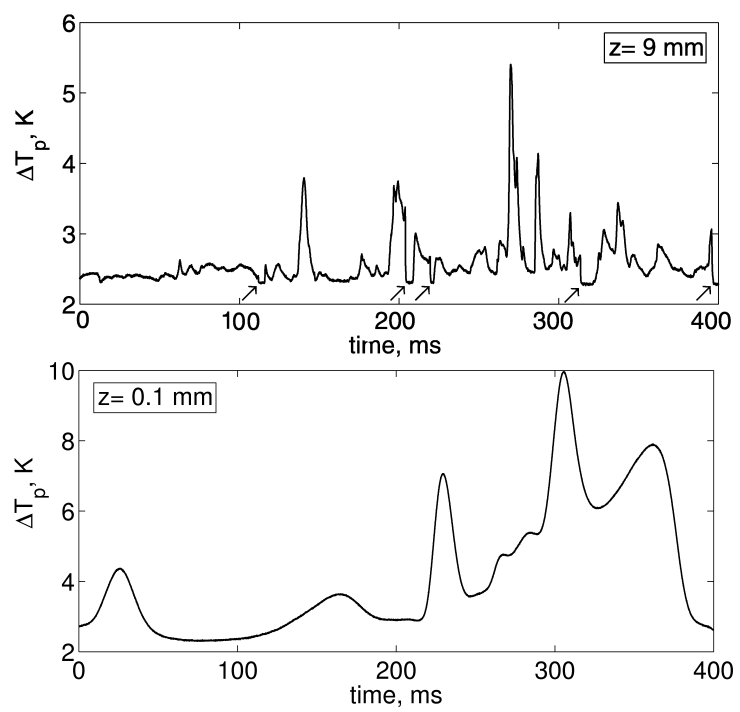

Figure 22. Measured local fluid temperature in low heat flux nucleate boiling of isopropanol (3.5 W/cm ${ }^{2}$, see Fig.(10)) at $9 \mathrm{~mm}$ (left) and $0.1 \mathrm{~mm}$ (right) distance to the heater surface; arrows indicate vapor contacts; $\Delta T_{p}$ $=\mathrm{T}_{\text {probe }}-\mathrm{T}_{\text {sat }}$.

In nucleate boiling at low heat flux (small number of active nucleation sites), strong temperature fluctuations are found in the liquid, Fig.(22). The liquid is always superheated, with maximum dimensionless superheats $\mathrm{T}_{\mathrm{p}}^{*}=\left(\mathrm{T}_{\text {probe, } \max }-\mathrm{T}_{\text {sat }}\right) /\left(\mathrm{T}_{\text {heater }}-\mathrm{T}_{\mathrm{sat}}\right)$ up to 0.8 at $\Delta \mathrm{T}=\mathrm{T}_{\text {heater }}-\mathrm{T}_{\text {sat }}=20 \mathrm{~K}$. Vapor contacts were not observed at $\mathrm{z}=0.1 \mathrm{~mm}$ but are found at $\mathrm{z}=9 \mathrm{~mm}$ distance. During a vapor contact, which is indicated by the attached MOP, the temperature drops down quite fast. However, the lowest temperature measured inside the vapor $\left(\Delta \mathrm{T}_{\mathrm{p}}=\mathrm{T}_{\text {probe }}-\mathrm{T}_{\text {sat }} \approx 2 \mathrm{~K}\right)$ is always above saturation temperature. It is also certainly above the minimum value needed for a bubble of the estimated diameter to exist according to theory. The temperature during a vapor contact remains approximately constant in nucleate boiling. This is different in other boiling regimes, as will be shown later. After a vapor contact, the probe heats up again quite rapidly.

The temperature changes within the liquid at low heat flux and close to the heater surface $(z=0.1 \mathrm{~mm})$ are relatively slow. This is reasonable as the fluctuations are expected to be caused by natural convection and also by improved convection due to bubble nucleation, growth and rise. However, at the small distance, the temperature field seems to be not much affected by turbulence due to bubble dynamics in the present case. At $9 \mathrm{~mm}$ probe distance, the fluctuations are much more rapid. The measured liquid superheat near to the interface can be up to $5.5 \mathrm{~K}$ (close to $4 \mathrm{~K}$ superheat near an interface can be found in Fig.(22), left; see 2nd arrow from left). This holds even if we take into account that the measured temperature inside the bubble can potentially be affected by errors because of a liquid film which may be present on the MTCP probe surface after penetrating the interface. It is currently not fully understood whether this effect is important - and if this is the case, to which extent - or not (for a detailed discussion of the measurement accuracy see chapter (4.4.6)).

Temperature fluctuations at $9 \mathrm{~mm}$ probe distance within the liquid are much faster than close to the heater which can be explained as follows. The level of turbulence in low heat flux nucleate boiling (isolated bubbles) is expected to increase with increasing distance to the heater because the bubbles are accelerated. The bubbles should therefore mix the liquid which leads to faster temperature changes and also better temperature equalization within the fluid. The total temperature fluctuation amplitude should therefore decrease with increasing distance. It is furthermore likely that further away from the superheated boundary layer above the surface the temperature amplitudes are anyway smaller than very near to the surface.

\section{MTCP Results for Film Boiling of Isopropanol}
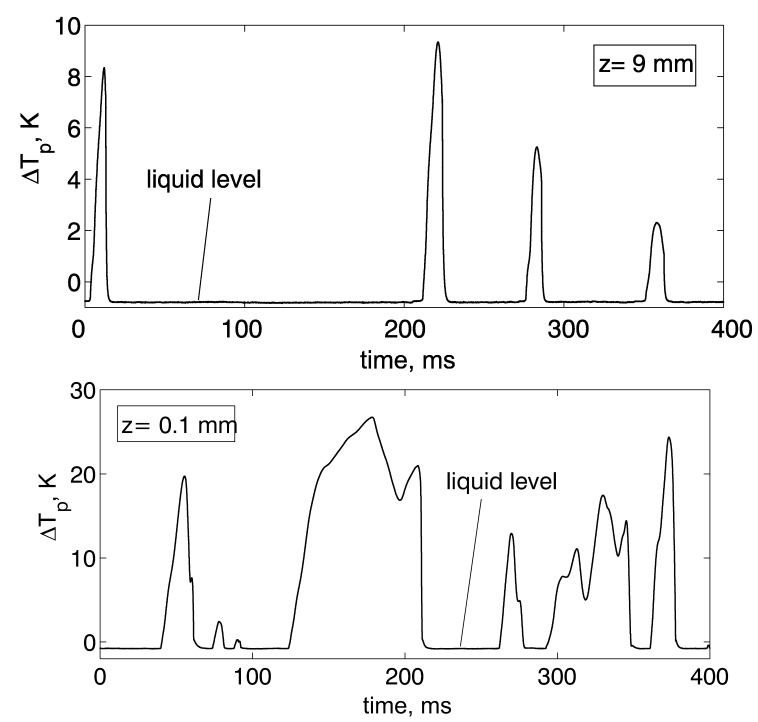

Figure 23. Measured local fluid temperature in film boiling of isopropanol ( $\Delta \mathrm{T}=71 \mathrm{~K}$, see Fig. (10)) at $9 \mathrm{~mm}$ (left) and $0.1 \mathrm{~mm}$ (right) distance to the heater surface; $; \Delta T_{p}=T_{\text {probe }}-T_{\text {sat }}$. 
In film boiling, see Fig.(23), the characteristics are opposed to the behavior in nucleate boiling at low heat flux. Unlike nucleate boiling, the liquid temperature remains constant. It is about the pool temperature and approximately independent of the probe position. The liquid temperature is slightly subcooled by about $0.5 \mathrm{~K}$ which represents the main pool conditions. A slight increase towards saturation temperature is detected for decreasing distance of the probe. The measured vapor temperature exhibits very large fluctuations. Vapor superheats of more than $40 \mathrm{~K}$ have been found at a heater superheat less than $80 \mathrm{~K}$. The measured maximum superheat inside the vapor decreases with increasing probe distance.

In film boiling no liquid contact occurs at the heater surface. The absence of liquid contacts at the heater surface thus prohibits the liquid to be heated above saturation temperature as observed by the MTCP. The maximum possible temperature can be expected to be saturation temperature at vapor-liquid interfaces. This is confirmed by the measurements which show the small subcooling in our pool $(0.5 \mathrm{~K})$. For the vapor, we get quite different conditions. The vapor film at the heater surface has direct contact to the hot surface, consequently its temperature is well above saturated conditions. If a bubble leaves the film it obviously contains this superheated vapor. It is reasonable - and confirmed by the experiments - that with increasing probe distance the vapor cooles down due to convection and conduction inside the bubbles since the interface temperature of the bubbles can be assumed to be at about saturated conditions. Because of the small heat capacity of the vapor inside the bubble little heat is removed from the vapor and transferred to the interface.

In Fig.(23) different durations of vapor contacts for $9 \mathrm{~mm}$ and $0.1 \mathrm{~mm}$ probe distance are observed. At $9 \mathrm{~mm}$ distance, the probe certainly detects large rising bubbles. At $0.1 \mathrm{~mm}$ distance, both short and long vapor contacts are found. Here, the probe is possibly located near to the interface of the wavy vapor film at the heater surface. Contacts with the relatively slow-moving interface especially for the case of a bubble growing and departing from the film with low initial velocity - are expected to last longer than for a rising bubble.

\section{MTCP Results for the Critical Heat Flux of Isopropanol}
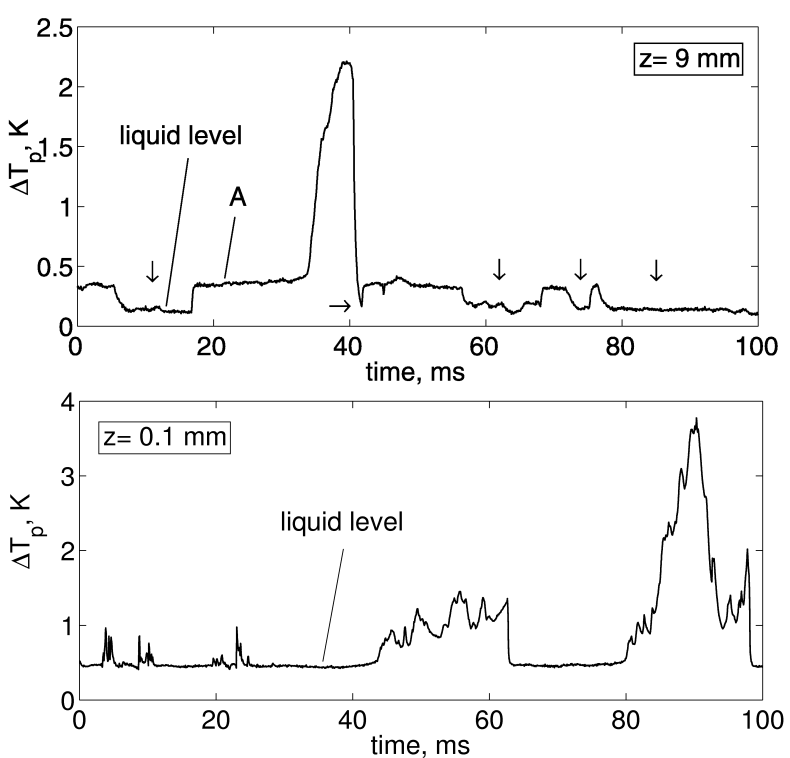

Figure 24. Measured local fluid temperature at CHF of isopropanol at 9 $\mathrm{mm}$ (left) and $0.1 \mathrm{~mm}$ (right) distance to the heater surface; arrows indicate liquid contacts; $A$ : see chap. 4.4.6); $\Delta T_{p}=T_{\text {probe }}-T_{\text {sat- }}$
At CHF, as can be expected from MOP experiments (see chap. (4.3)), an increased number of vapor contacts can be found. This is confirmed by the plots in Fig.(24). Note, that the plotted interval in Figs. (24) and (25) is now $100 \mathrm{~ms}$. As opposed to the characteristics in nucleate boiling, the detected vapor temperature exhibits some temperature fluctuations with much higher amplitudes than observed in nucleate boiling. Furthermore, vapor temperature at CHF appears to be always higher than the liquid temperature. The relatively weak increase of surface superheat between nucleate boiling and CHF $(\approx$ $10 \mathrm{~K}$, see Fig.(10)can certainly not explain this characteristic change. As described in the previous chapter, very high vapor superheats are observed in the film boiling regime where vapor covers the entire surface. If we assume unstable vapor patches around CHF to exist for short periods on a given surface area, the vapor above this patch would gain a higher temperature. After lift off, this elevated vapor temperature can be expected inside the bubble for a short period until heat transfer to the interface causes the temperature to decrease. The existence of unstable vapor patches even below CHF has been proven by the MTC experiments (see. chap. (4.2)). Therefore, the measured vapor temperature excursions can be assumed to be the result of the dry areas on the heater surface. The transition from "hot liquid" and "cold bubbles", as observed in low heat flux nucleate boiling (Fig.(22)) to the opposite case at CHF and towards film boiling occurs most likely gradually. To prove this, more measurements and analyses are necessary.

The liquid temperature at CHF fluctuates much less than in nucleate boiling. We assume that this is due to the strong increase of nucleation site density and thus increased turbulence and interfacial area density. Hence, increased mixing as well as locally available interfaces which act as "heat sinks" lead to the observed liquid temperature characteristics.

A discussion of the intermediate level A in Fig.(24), left, is given in chap. 4.4.6).

\section{MTCP Results for Transition Boiling of Isopropanol}
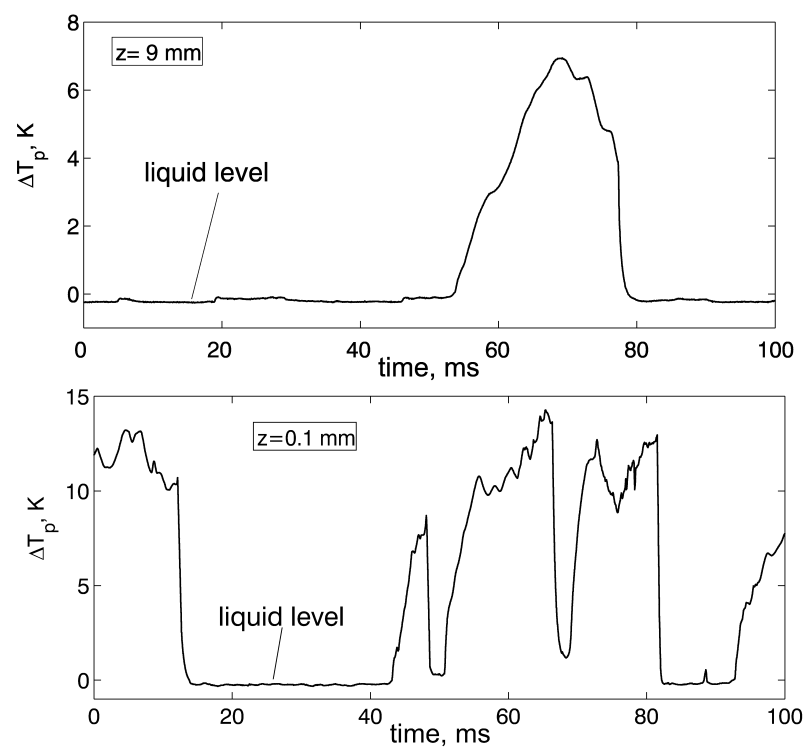

Figure 25. Measured local fluid temperature of isopropanol in transition boiling ( $\Delta T=42 \mathrm{~K}$, see Fig. 10) at $9 \mathrm{~mm}$ (left) and $0.1 \mathrm{~mm}$ (right) distance to the heater surface; $\Delta T_{p}=T_{\text {probe }}-T_{\text {sat }}$.

Temperature traces measured in steady-state transition boiling are depicted in Fig.(25). The sequences plotted represent low heat flux / high superheat transition boiling near the Leidenfrost point (Fig.(10), $\Delta \mathrm{T}=42 \mathrm{~K}$ ). Thus it is not surprising that the signal has 
similarities with those observed in film boiling. But there are also important differences. First, the maximum detected vapor superheat in transition boiling is less than in film boiling if we compare the signals at both distances. This finding is to be expected as the driving $\Delta \mathrm{T}$ is lower. Second and more important, the signal dynamics are different. This is more obvious at a probe distance of $0.1 \mathrm{~mm}$. The temperature traces exhibit many rapid fluctuations within the vapor - and also more vapor contacts - and the "smoothness" of the signal is lower than observed in film boiling. Furthermore, the signals appear more irregular than in film boiling. Both findings indicate that some mechanism involved generates more "turbulence" or, in other words, a locally less-steady heat transfer mechanism. Analysis of MTC experiments in transition boiling (see Fig.(15)) prove that rewetting and dryout processes are very rapid in this region. Because the driving $\Delta \mathrm{T}$ is very large compared to nucleate boiling, the local evaporation process is very fast. Thus, the local vapor generation during the short and intermittent surface wetting events is expected to be associated with local high vapor velocity. This leads to a high level of turbulence and thus rapid temperature fluctuations within the vapor as detected by the MTCP. It is furthermore not impossible that very small droplets created by the explosive evaporation process touch the probe during its contact with the vapor phase. This mechanism may also affect the vapor temperature behavior during a local dryout of the heater surface at about CHF (see Fig.24)).

\section{Discussion of MTCP Measurement Accuracy}

For the complex temperature measurement being carried out here the real measurement accuracy is not easy to determine. The accuracy is affected - additionally to the usual error components like systematic and statistic errors - also by the thermal inertia of the sensor and a liquid film on the MTCP which could be present after a liquid $\rightarrow$ vapor phase change. Our analysis of the signals reveal that amplitude errors due to insufficient response time of the sensor are not very important. This holds for measurements within the liquid and for a vapor $\rightarrow$ liquid phase change. It holds also for measurements within vapor - which is expected to be the most critical measurement situation with regard to response time - or for a liquid $\rightarrow$ vapor phase change. For any of the possible cases, signal periods are found during which the temperature settles and / or exhibits faster fluctuations superimposed to the general trend. These superimposed fluctuations would be impossible to detect for a response-time governed temperature signal (a good example is given in Fig.(25); note that the amplitude at $9 \mathrm{~mm}$ is comparable to film boiling but plotted for a shorter duration here. Any error due to MTCP response time would lead to an underestimation of the temperature amplitude. The rate of temperature change, especially during a phase change, could be even faster in reality than the measured ones. Calculation of the power spectral density reveals that high frequency signal components above $10 \mathrm{kHz}$ due to boiling are present in the temperature signal. Thus, filter cutoff frequency $(12.5 \mathrm{kHz})$ could be too low to let pass the highest frequency components of real temperature changes detected by the probe.

Measurement errors due to a liquid film atop the MTCP surface are difficult to quantify. This holds even more as we found sequences which point to the presence of a vapor film and also sequences which contradict this assumption. Careful experiments and detailed dynamic simulations of the MTCP are necessary to obtain the definite dynamical effects if a liquid film is present atop the MTCP surface. These tasks are beyond the scope of our present investigation but the effects will be analyzed in more detail in the future.

Here we discuss briefly some possible cases in order to get a rough estimate of the error bounds. For a dry probe, the measured temperature should not be affected except due to the dynamical properties of the sensor and the electronics used. For a wetted probe, we consider two different cases which are representative for the nucleate and film boiling regimes. Here, we assume the vapor pressure inside the bubble to be at pool pressure $\mathrm{P}=\mathrm{p}_{\infty}$ regardless of the pressure difference and superheat necessary to sustain a bubble due to the interfacial tension at the bubble's surface since the difference is very small for our conditions.

1. A phase change superheated liquid $\rightarrow$ saturated vapor takes place at the probe tip. Unlike interfacial tension at the interface of the bubble itself, interfacial tension may play an important role at the surface of the film atop the probe as the diameter of the probe is very small $(\approx 16 \mu \mathrm{m})$. If we assume the shape at the probe tip to be semi-hemispherical, we can calculate the pressure difference across the interface using the Young-Laplace equation (Kandlikar et al, 1999). The pressure difference under these conditions is about 46 mbar which corresponds to a shift of the film's saturation temperature of about $+1 \mathrm{~K}$. Most of the pressure difference acts on the liquid side but the pressure of the vapor above the interface with konvex curvature is also affected - it's pressure is slightly increased with respect to $\mathrm{p}_{\text {bubble. }}$ This leads to a complex coupled problem including evaporation at the interface, heat transfer from the interface to the bubble due to conduction and convection as well as mass transfer due to vapor flow perpendicular to the interface. The process is even more complicated as the interface's curvature and thus film pressure changes with a change of film thickness and probably mass transfer resistance at the interface plays also a role.

2. A phase change saturated liquid $\rightarrow$ superheated vapor takes place at the probe tip. We assume the same conditions regarding the pressure conditions. Unlike for the case (1), the direction of the heat flow both within the sensor and more important also inside the vapor are in the inverse direction here. Still, we have the coupled mechanisms of heat and mass transfer at the interface. Being opposed to the case (1), we have a significant temperature gradient between bubble and film which definitely forces the liquid film to evaporate.

In low heat flux nucleate boiling (case 1) we measure always a higher temperature than $\mathrm{T}_{\text {sat }}+1 \mathrm{~K}$ thus is seems likely that the vapor temperature is not saturated but superheated. At current, we cannot estimate its true superheat in nucleate boiling with a liquid film present at the probe tip. In boiling regimes where superheated vapor and about saturated liquid can be present (case (2) which is applicable to CHF, transition boiling, film boiling and possibly high heat flux nucleate boiling), the real vapor temperature is expected to be measured after some delay caused by the time necessary to evaporate the film. This means for the conditions assumed that a liquid film could lead at the worst only to an underestimation of the real temperature. The dryout of a liquid film atop the probe is expected to cause the intermediate temperature level for the vapor (denoted by "A" in Fig.(24) left). The temperature here is about constant for about $15 \mathrm{~ms}$ until the temperature rises quite fastly. This behavior can be explained with the dryout of a liquid film atop the MTCP.

\section{Mechanistic Models}

The rather sophisticated experiments with microsensors offer a chance to develop physically based boiling heat transfer models which include phenomena and information explored by the microsensor techniques. A step forward towards physically based models is the microlayer theory (Wayner Jr., 1994; Stephan and Hammer, 1994) It yields good agreement with experimental data as long as there is no interaction between the bubbles. 
In boiling regimes at higher heat fluxes up to the critical one and beyond it, the microlayer theory cannot be applied directly to predict heat transfer because of bubble interactions and the dry spot generation beyond CHF, respectively. Nevertheless the idea of evaporation in the contact line region, where the main part of the heat is removed from the heater in a boiling system, can be extended to regions of higher wall superheats as already proposed by Nishio et al., 1998, for the region around CHF. In the following chapter some remarks on a model are made along these lines. It needs data from the microsensor experiments. This holds also for a second model summarized in the subsequent chapter. Here, the instability of a dry spot ensemble on the heater surface is claimed to be the triggering effect for the occurrence of CHF.

\section{An Interfacial-Area-Density Model}
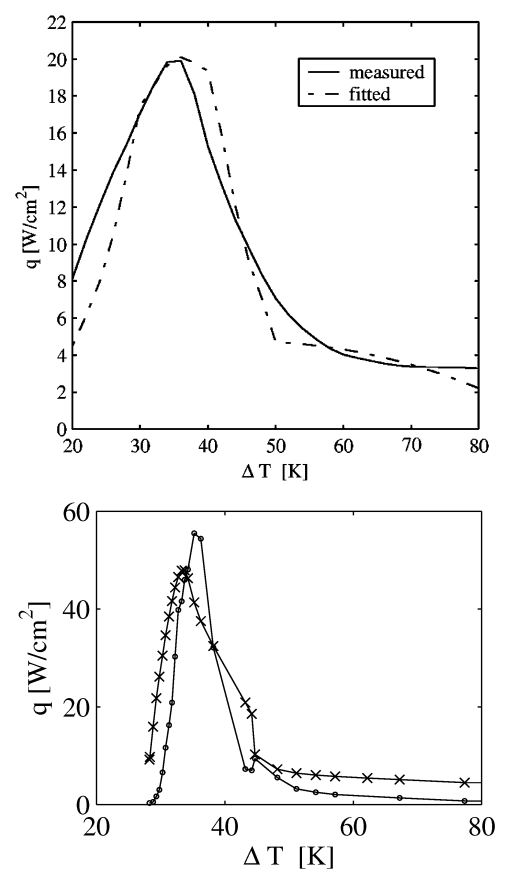

Figure 26. Measured (Fig. (9)) and predicted boiling curves: left: for FC-72 (Lüttich et al., 2004) right: for isopropanol (Lüttich et al., 2004).

Evaporation near the contact line area seems to be the governing mechanism for boiling. This was experimentally proved for the low superheat region Stephan and Hammer, 1994) and by Nishio et al., based on visual observations of boiling structures on a thin sapphire heater in the high heat flux region around CHF. Lüttich et al., 2004 and Lüttich et al., 2004, propose that this concept should be used for a unifying mechanistic model of the entire boiling curve, because it is reasonable to assume that in other boiling regions the contact line density (length of contact line per unit area) and the corresponding interfacial area density near the contact line also governs the boiling mechanisms. In transition boiling, for instance, we have the threephase contact line around the dry spots and in addition many of those lines in the evaporating wet spots. Measurements with optical probes enable to some extent a verification of this modeling concept. Lüttich et al. use our heat transfer data and optical probe data from experiments with FC-72 (2004) and with isopropanol (2005), respectively.

Based on own studies and those from the literature about vapor generation and two-phase kinematics near the heating surface, Lüttich et al., 2004, 2005, conclude that the interfacial area density $A_{i}$ (interfacial area per unit volume) or its flux $\operatorname{Aiv}_{c}$ (time rate of change of the void fraction, determined simply by the sum of positive and negative signs of the normal interfacial velocity $v_{c}$ ) are the governing parameters for evaporation heat transfer. The measurement of $A_{i}$ would require a four-sensor probe, as theoretically shown by Kataoba and Serizawa, 1990. However, in our experiments only a single probe has been used [note that the 4tip probe (Fig. (6)) would not be applicable since the tips are not suitably distributed in space. A suitable probe was not yet designed]. Therefore, the authors were forced to a simplification. According to the studies on the two-phase kinematics mentioned above, there is an indication that the vapor contact frequency $\mathrm{f}$, which was also measured in our experiments with FC-72 and isopropanol, is related to the interfacial area density.

The usefulness of the above concept to correlate heat transfer along the entire boiling curve has been tested by the authors on the basis of a simple geometric model consisting of circular dry spots (vapor stems) on the surface. They are separated in the low superheat region and overlapped at higher superheats.

The very simple approach by the authors yields a reasonable fit of the measured boiling curves (Figs. (9) and (10)) for FC-72 and isopropanol, respectively, as shown in Fig. (26). Note that the subject of this study was simply to prove by means of experimental data that evaporation around contact lines is the governing mechanism along the entire boiling curve. Better predictions of boiling curves require more sophisticated measurements and theoretical studies along the lines of the concept under consideration.

\section{A Reaction-Diffusion Model for the CHF Mechanism}

The understanding of the phenomenology of critical heat flux (CHF) is still controversial. The most common models, Zuber, 1958, theory of hydrodynamic instability and Haramura and Katto, 1983, macrolayer dryout model are essentially based on hydrodynamic scenarios. Despite a reasonable good agreement between experimental results and predictions of CHF based on these two models, a number of key factors definitely influencing boiling heat transfer and CHF are disregarded in these models (Sadavisan et al., 1995). In particular they do not consider the dynamics of interactions between fluid patterns and heat conduction inside the heater. In order to address this problem, Bluem et al., 1999, suggest a novel unifying approach to the development of a mechanistic model for the boiling regimes around CHF based on the mathematical theory of reaction-diffusion systems. They start with the assumption that the macroscopic boiling phenomena, represented by the boiling curve, are caused by the dynamics of formation and propagation of dry spots on the heater surface. The dynamics are caused by the interaction of heat conduction in the heater, the phase transition on the heater surface as well as the fluid dynamics in a small zone close to the heater surface. These highly transient elementary physical phenomena result in the macroscopic non-linear boiling curve if suitable space and time averaging is carried out.

This modeling approach distinguishes two different classes of elementary phenomena, namely the formation of dry spots on the one hand and their stability and dynamics on the other hand. The study is not focused on the former phenomenon but it assumes that dry spots of certain geometrical extension have occurred by some mechanism. Clearly, a further evaluation of our optical probe results and microthermocouple data can improve our knowledge of this phenomenon. The authors' focus is on the stability of an instantaneously existing ensemble of dry spots on the boiling surface. The model assumptions are depicted in Fig. (27). 


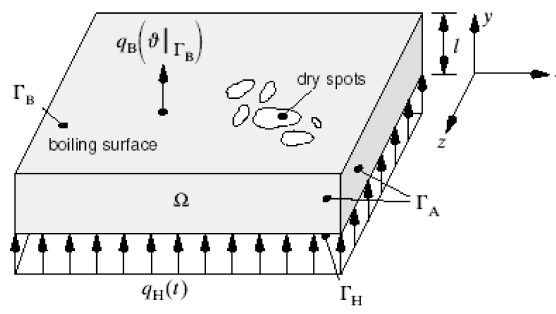

Figure 27. Heater with dry spots on the surface.

The behavior of the flat heater of thickness 1 is governed by the heat conduction equation in three spatial dimensions $(\mathrm{x}, \mathrm{y}, \mathrm{z})$. External heating, $\mathrm{q}_{\mathrm{H}}(\mathrm{t})$, and heat removal by boiling, $\mathrm{q}_{\mathrm{B}}\left(\vartheta / \Gamma_{\mathrm{B}}\right)$, occur on opposite sides of the heater element. The peripheral surface $\Gamma_{A}$ of the heater is assumed to be adiabatic. The heat flux $\mathrm{q}_{\mathrm{B}}\left(\vartheta / \Gamma_{\mathrm{B}}\right)$ on the heater surface, representing spatiotemporally varying heat transfer, depends (among other factors) on the liquid and vapor contacts at the boiling surface. For simplicity, the authors assume a linear relation between heat flux and temperature difference with different slopes in different boiling regimes, as boundary conditions.

The resulting model consists of the heat conduction equation with material constants and suitable boundary and initial conditions. Unfortunately, analytic results on spatiotemporal patterns which reflect the dynamics of dry spots are not yet available for the threedimensional case. The attention is therefore restricted to thin heaters with $1 \rightarrow 0$ to allow for one- or two-dimensional modeling.

The main results from this study can be summarized as follows: A dry spot expansion is accompanied by a temperature wave in the surface region of the heater. Necessary conditions for the occurrence of such temperature waves have been identified by applying known results from the theory of reaction-diffusion problems as well as by numerical simulation. The investigations show that a single dry spot can only cause the transition to film boiling for thin heaters such as wires or foils. For instance, a dry spot of an extension of only some tenth of a mm is necessary in case of a thin copper heater $(0.1 \mathrm{~mm}$ thick) at a heat flux of $\mathrm{q}_{\mathrm{H}}=9 \times 10^{5} \mathrm{~W} / \mathrm{m}^{2}$ at water pool boiling to trigger a temperature wave and, hence, CHF (see also Fig. (28).
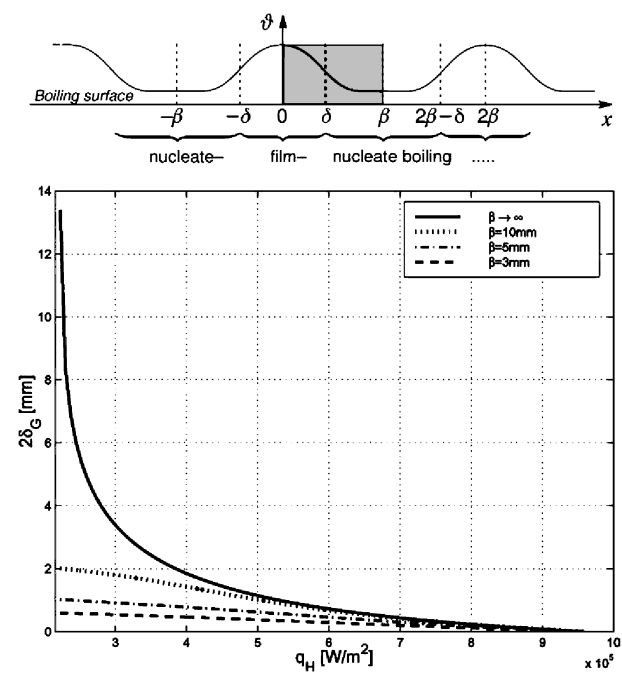

Figure 28. Distribution of dry spots and stability limits for water pool boiling on a copper foil with $0.1 \mathrm{~mm}$ thickness.

With increasing thickness of the heater the explanation of a single dry spot causing transition from nucleate to film boiling looses its plausibility. For example, a dry spot of an extension of more than $8 \mathrm{~mm}$ would be required in the same system in case of a copper heater of $10 \mathrm{~mm}$ thickness to cause this effect.

It is further shown that the size of dry spots required to trigger CHF is diminished tremendously if a number of cooperating dry spots are assumed to exist on the boiling surface. In the upper part of Fig.(28) regular distributed dry spots of size $2 \delta$ and distance $\beta$ and the corresponding temperature profile on the surface are assumed. The result for a heated copper foil of thickness $1=0.1 \mathrm{~mm}$ is shown in the lower part of Fig. (28). Given a heat flux $\mathrm{q}_{\mathrm{H}}$ of, say, $3 \times 10^{5} \mathrm{~W} / \mathrm{m}^{2}$ the system is stable up to a maximum dry spot size of $2 \delta \approx 3.5 \mathrm{~mm}$ if only one single dry spot exists $\beta \rightarrow \infty$. For several dry spots with a distance of, say, $\beta=3 \mathrm{~mm}$ the system becomes unstable and CHF is triggered if the dry spot size exceeds $2 \delta \approx \mathrm{mm}$.

The results for thick heaters and for cooperating dry spots mentioned above have been obtained by numerical or analytical computations with simplified heater models. Future work will concentrate on numerical stability analysis of a three-dimensional heater. Powerful adaptive numerical methods, which are not available to date, are a prerequisite to success for this approach. Such results combined with an understanding of the mechanisms of dry spot formation could lead to a physically sound mechanistic model for CHF under steady-state and transient heating conditions. A substantial help on the way towards this model will be data from multitip-optical probes and microthermocouples. However, we need a simplified access to data like dry spot sizes and dynamics. Models for such data are required which can be validated by the microsensor data.

\section{Conclusions}

Based on all the presented results some conclusions can be drawn on the behavior of boiling curves, on some mechanisms of heat transfer in the different boiling regimes and on some new aspects of modeling the heat transfer in boiling.

\section{Boiling Curves Under Steady-State and Transient}

\section{Conditions}

Under steady-state pool boiling conditions with a good control system to stabilize boiling in the transition region and a clean heater surface, no hysteresis has been observed in the transition region for both well wetting fluids and fluids with a larger contact angle. Small disturbances in the transition boiling curve have been observed with water and isopropanol. This may result from a non-ergodic boiling behavior on the heater surface. Clusters of dry patches occur which change their configuration with the wall superheat. The size of the clusters is smaller than the heater surface area. It is unlikely that the clustering effect is caused by insufficient controlling but we are not yet able to give a physical/mathematical explanation of this effect. For a surface with contamination, boiling curves are not reproducible.

Under transient conditions a hysteresis is observed: Heating transients yield always higher heat fluxes than cooling transients at the same wall temperature. At fast transients enormous differences in the heat fluxes compared with the steady-state case have been observed.

A comparison of optical probe signals and microthermocouple signals (Hohl, 1999; Hohl and Auracher, 2000); in steady-state FC72 experiments enables an estimate of the density of nucleation sites. It turns out, e.g., that the minimum nucleation site density near CHF is about $3 \times 10^{8} \mathrm{~m}^{-2}$. Regarding the uncertainty of this estimate we may conclude that the nucleation site density is between $10^{8}$ and $10^{9} \mathrm{~m}^{-2}$. This is in the order of magnitude of the results by Pinto et al., 1996, who observed $4 \times 10^{7}$ nucleation sites per $\mathrm{m}^{2}$ in propane boiling at a heat flux of $5 \mathrm{~W} / \mathrm{cm}^{2}$, which is below CHF. 
The high density of active nucleation sites in the region between fully developed nucleate boiling and CHF and the resulting highly turbulent two-phase boundary layer let us conclude that the strong increase of heat flux in heating transients and vice versa in a cooling process is mainly due to the intensive two-phase convection heat transfer from the wall to the bulk. This is most likely not primarily because of a change in the two-phase structure (i.e., nucleation site density, bubble frequency, void fraction distribution etc.) near the wall, which is not significantly affected by temperature transients as can be estimated by a simple example: At a bubble departure frequency of, say, $100 \mathrm{~Hz}$, the temperature rise of the heater surface during the period between two bubbles is only $0.5 \mathrm{~K}$ at the fastest transient of $50 \mathrm{~K} / \mathrm{s}$ (Fig. (12)). Hence in a first approach we can assume that vapor generation and wetting mechanisms are much faster processes and not affected by a temperature change during a transient. Rather, the strong change of heat transfer during a transient is mainly due to the instantaneous temperature gradient in the fluid at the heater surface which is increased or decreased during the transient modes. Hence, the highly turbulent microconvective transfer of energy is intensified if it takes place in a temperature field with steeper gradients caused by transient heating or with weaker gradients in the cooling mode. Clearly, we have no direct experimental indication for steeper or weaker temperature gradients during the transients. Furthermore our measurements of the twophase structure near the wall and its behavior during transients are not precise enough to exclude an error in the above statement Therefore, more precise measurements along the line presented in this report should be carried out to support this conclusion. Besides, an estimate reveals that unsteady-state heat conduction to the liquid cannot explain the strong increase of heat flux during a heating transient.

Results obtained with microthermocouples (Hohl and Auracher, 2000; Hohl, 1999) let us furthermore assume that at wall superheats beyond CHF the two-phase structure at a given wall superheat is not independent of the heating or cooling rate. The faster the transient the stronger the delay in the two-phase structure formation. This could be one reason for the deviation of heat flux between the transient and steady-state case in the transition and film boiling region. But we need more experiments with our microsensors to gain a better insight in the physics responsible for this deviation.

\section{The Structure of the Macrolayer}

The data by Hohl et al., 1998 with FC-72 and the more recent measurements by Buchholz et al., with isopropanol (both see Section (4.3.2) and (4.3.3) give us now a much clearer insight in the nearfield region above the boiling surface (see Figs.(18)-(20)). As several authors assume, there is a liquid rich layer. The void fraction is very small at the surface but with increasing tendency towards higher superheats. It is quite reasonable that this "surface vapor fraction" is associated with the non-evaporating area in the center of attached bubbles. With increasing superheat the surface fraction of these areas increases because of the increase of active nucleation sites. Already before reaching CHF some bigger dry patches occur probably due to coalescence effects on the surface, as observed by Buchholz et al., 2004. Away from the surface the void fraction increases until a maximum is reached. This may be explained as follows: Assuming the region between surface and void fraction maximum is the one of growing but attached bubbles. Then we would measure in the time and space average (i.e. in the ergodic case) an increase in void fraction in direction away from the surface. Assuming a departure diameter $\mathrm{d}_{\mathrm{B}}$ and imagine a layer at a distance of $d_{B} / 2$, cutting bubbles still growing, and those which are departing, then we would measure the maximum void fraction not necessarily at a distance $d_{B} / 2$ but likely not far away from it. Anyway, the peak distance to the surface is most likely related to the departure diameter. This is supported by the observation that peak distances to the surface of FC-72 (Fig. (18)) are smaller than those of isopropanol (Fig. (20)) and this holds also for the departure diameters of both fluids. It was furthermore observed that the peak distances to the surface for both fluids decrease with increasing wall superheat. Having the above model in mind this might be an indication that with increasing superheat the bubble shape becomes more and more flat, i.e. extended parallel to the surface during the growing period. Studies in the literature support this conclusion (e.g. Mitrovic, 1985). An explanation of the decrease in void fraction after the peak which was observed in the FC-72 experiments (Fig. (18)) and especially in the more extended measurements with isopropanol (Figs. (19)) and (20)) is in a first glance not easy to explain. More detailed analyses are required to find an answer.

The existence of stationary vapor stems in the liquid rich area (macrolayer) is rather unlikely, as always, even at the smallest distances, very short vapor contacts have been detected. Even the very thin tip ( $<1.5 \mu \mathrm{m}$ of our optical probe (Fig. (5)) did not observe signal characteristics which would indicate a vapor stem structure near the surface. The macrolayer region is obviously quite agitated in the higher heat flux regions. (Hohl and Auracher, 2000, observed in the FC-72 experiments at a distance of $0.05 \mathrm{~mm}$ from the heater up to 600 vapor contacts per second. Active nucleation sites are not locally fixed for a longer period. The activation and deactivation seems to occur within a wide frequency range.

\section{Non-Equilibrium in the Two-Phase Structure}

The microthermocouple probe experiments reveal that a strong thermodynamic non-equilibrium exists in the two-phase layer above the heater. For isopropanol the following main results have been found.

In nucleate boiling the liquid above the heater is significantly superheated with pronounced but slow temperature fluctuations near the surface $(\mathrm{z} \sim 0.1 \mathrm{~mm})$ in the region with a small number of active nucleation sites. Thus a significant portion of the total heat flux is transferred by convection. For higher heat fluxes, faster liquid temperature fluctuations with smaller amplitudes at a lower liquid temperature level have been found. For the vapor, the opposite trend is observed: Small superheats exist in the bubble and strong superheats in the surrounding liquid in low heat flux nucleate boiling. Approaching CHF the vapor superheat in the bubbles increases whereas the surrounding liquid tends towards saturation.

At critical heat flux the liquid temperature is close to saturation temperature. It is assumed that this is due to the high number of active nucleation sites and thus increased turbulence and interfacial area density. Both effects promote a temperature equalization in the liquid phase. The vapor temperature inside the bubbles is always above saturation. Superheats of up to $10 \mathrm{~K}$ are observed which indicate the existence of dry patches with superheated vapor on the surface.

In transition boiling the superheat inside the bubbles is higher than at CHF and longer vapor sequences are observed. The liquid temperature above the surface is at pool temperature already at a distance of $0.1 \mathrm{~mm}$ to the surface.

In film boiling at a distance of $0.1 \mathrm{~mm}$ to the surface vapor superheats inside the bubbles in excess of $40 \mathrm{~K}$ at wall superheats < $80 \mathrm{~K}$ have been found. The superheat decreases with increasing distance to the surface due to heat transfer towards the bubble wall. At the vapor/liquid interface above the heater the MTCP detects no remarkable deviation from saturation.

The superheat in the vapor phase, observed already in intensive nucleate boiling, is an unexpected result looking at usual assumptions in the literature. This holds especially if we take into 
account that already at CHF up to $10 \mathrm{~K}$ superheat is observed with increasing tendency to film boiling where superheated vapor of more than $40 \mathrm{~K}$ was measured inside the bubbles. An estimate of the measurement accuracy indicates that the real superheat could be even somewhat higher.

\section{Mecanistic Models}

The experimental results with microsensors confirm that evaporation in the contact line region, where the main part of heat is removed from the heater surface, is a promising modeling concept for the entire boiling curve. Studies by and 2005, propose that the interfacial area density $A_{i}$ near the heating surface should be used as governing modeling parameter. It seems that the contact frequency measured near the surface by an optical probe is a good measure for the contact line density. But better results, namely those for $A_{i}$, can be expected if measurements with a 4-tip probe with the tips properly distributed in space are available.

The microsensor experiments can also contribute to a more physically sound model for CHF. (Blum et al., 1999), propose a model based on the mathematical theory of reaction-diffusion systems. Their concept is that heat transfer in the CHF region is caused by the dynamics of formation and propagation of dry spots on the heater surface. The dynamics are caused by the interaction of heat conduction in the heater, the phase transition on the heater surface as well as the fluid dynamics in a small zone close to the heater surface. The authors concentrate not on the formation of dry spots but on their stability and dynamics. Finally it can be shown under simplified mathematical conditions that for a given ensemble of dry spots on the heater surface a stability limit exists at which the dry spots start to grow and trigger CHF. This model requires experimental information on the size and dynamics of dry spots on the surface, like the data extracted by Buchholz et al., from their microthermocouple experiments (see also chapter (4.2)). Clearly, we need also an answer--in terms of a good model-about the formation of dry spots on the surface. Until now, this problem is not included in Blum's et al.'s theory.

\section{Needs for Further Studies}

Measurements with microsensors in the nearfield above and below the heater surface yield key data for the development of mechanistic models for boiling in the different regimes. The results presented in the present report contribute already to some steps forward in the understanding of this very complex process. There are still a lot of already collected raw data waiting to be evaluated to give more precise answers to

- dry spot geometry, dynamics and stability;

- the space- and temporal-distribution of temperature and heat flux at the surface;

- the two-phase behavior above the heater to explain the void fraction distribution

in the steady-state case and the boiling curve characteristics under transient conditions;

- other problems mentioned in the text

However, the game is far from being over if we find the above mentioned answers. We need

- experiments with other fluids to solicitate the existing findings;

- a special 4-tip probe to evaluate the interfacial area density near the surface and models to predict this quantity;

- realistic models for the macrolayer above the heater;

- models for the formation of dry spots in the higher superheat regions, etc.
We are convinced that substantial progress is only possible if we tackle the problem from both the experimental and the theoretical end. Preferably, both approaches should be closely linked.

We studied here only boiling-phenomena on smooth surfaces. Heat transfer enhancement by structuring the surfaces has already a long history. Most of the basic phenomena occurring at smooth surfaces are also relevant at enhanced surfaces, but several additional problems have to be solved in these cases. Last but not least, in practical applications we have quite often boiling mixtures which bring some more parameters into the game. In summary there is still a lot to do but real progress requires studies of the fundamentals.

\section{Acknowledgements}

The authors highly appreciate financial support by the "Deutsche Forschungsgemeinschaft, DFG" in the frame of a joint research project on fundamentals of boiling heat transfer. They are also very grateful for the tremendous work of their doctoral students J. Blum, R. Hohl, T. Lüttich and graduate students: J.Judex, O.Koeppen, J.Pöthke, C.Hertel.

\section{References}

3M Company, Specialty Materials Europe Division, 2003, Brochure: "The Nature of Fluorinert ${ }^{\mathrm{TM}}$ Electronic Liquids".

Arosio, S., Bertola, V. and Fossa, M., 1999, "Comparative analysis of intermittent air-water flow structure by means of different measurement techniques", Proc. Two Phase Flow Modelling and Experimentation, Vol. 3, pp. 1359-1364.

Auracher, H. and Marquardt, W., 2004, "Heat transfer characteristics and mechanisms along entire boiling curves under steady-state and transient condition”, Int. J. of Heat Fluid Flow, Vol. 25, pp. 223-242.

Bar-Cohen, A., Watwe, A. and Arik, M., 2003, "Pool boiling critical heat flux in dielectric liquids", Proc. $5^{\text {th }}$ Int. Boling Heat Transfer Conf., Montego Bay, Jamaica, 4.-8. May.

Beckman, P., Roy, R. P., Velidandia, V. and Capizzani, M., 1995, “An improved fast-response microthermocouple”, Rev. Sci. Instrum., Vol. 66.

Beckman, P., Roy., R. P., Whitfield, K. and Hasan , A., 1993, "A fastresponse microthermocouple”, Rev. Sci. Instrum., Vol. 64, pp. 2947-2951.

Blum, J., Lüttich, T. and Maquardt, W., 1999, "Temperature wave propagation as a route from nucleate to film boiling", In. Celata, G. P., Dimarco, P., Shah, R. K.(Eds), Two-Phase Flow Modelling and Experimentation, pp. 137-144, Edizioni ETS, Pisa.

Blum, J., Marquardt, W. and Auracher, H., 1996, "Stability of boiling systems", Int. J. Heat Mass Transfer, Vol. 39, pp. 3021-3033.

Buchholz, M. and Auracher, H., 2002, "Improved optical probes and their validation for local measurements in two phase flow", Proc. GermanJapanese Workshop on Multphase Flow, Vol. Forschungszentrum Karlsruhe, Germany, FZKA-6759, pp. B1-B10.

Buchholz, M., Auracher, H., Lüttich, T. and Marquardt, W., 2005, “A study of local heat transfer mechanisms along the entire boiling curve by means of microsensors", Int. J. of Thermal Sciences, p. accepted for publication.

Buchholz, M., Lüttich, T., Auracher, H. and Marquardt, W., 2000, “ Steady-state pool boiling experiments with water between nucleate and film boiling", Proc. $3^{\text {rd }}$ European Thermal Sciences Conference, Vol. 2, pp. 761766.

Buchholz, M., LUttich, T., Auracher, H. and Marquardt, W., 2004, "Experimental investigation of local processes in pool boiling along the entire boiling curve", Int. J. Heat Fluid Flow, Vol. 25, pp. 243-261.

Delhayer, J-M., Semeria, R. and Flamand, J.-C., 1972, "Mesure du taux de vide local et des temperatures du liquid et de la vapeur en ecoulement avec changement de phase a l'aide d'un microthermocouple", Technical Report CEA-R-4302.

Golobic, I., Pavlov, E., von Hardenberg, J., Berry, M., Nelson, R., Kenning, D., and Smith, L., 2004"comparision of a mechanistic model for nucleate boiling with experimental spatio-temporal data", Chemical Engng. Research and Design, Part A: Trans. Of the Inst. Of Chem. Engineers, p. accepted for publication.

Gorenflo, D., 2003, "VLE measurements of thoroughly desgassed FC3284, Private communication. 
Haramura, Y. and Katto, Y., 1983, "A new hydrodynamic model of critical heat flux, applicable widely to both pool and forced convection boiling on submerged bodies in saturated liquids", Int. J. Heat Mass Transfer, Vol. 26, pp. 389-399.

Hohl, R., 1999, "Mechanismen des Wärmeübergangs beim transienten und stationären Behältersieden in gesamten Bereich der Siedekennlinie", PhD Thesis, Technische Universität Berlin, VDI Fortschritt-Berichte Series 3, No. 597.

Hohl, R., and Auracher, H., 2000, !Transient pool boiling experiments!,

Ed. F. Mayinger and B. Giernoth, Wiley-VCH-DFG, New York, 241-256.

Hohl, R., Blum, J., Auracher, H., and Marquardt, W., 1998, Characteristics of liquid-vapor fluctuations in pool boiling at small distances from the heater", Proc. 11. Int. Heat Transfer Conf., Vol. 1.

Hohl, R., Blum, J., Buchholz, M., Lüttich, T., Auracher, H., and Marquardt, W., 2001, Model-based experimental analysis of pool boiling heat transfer with controlled wall temperature transients", Int. J. Heat Mass Transfer, Vol. 44, pp. 2225-2238.

Höhmann, C. and Stephan, P., 2002, microscale temperature measurement at an evaporating liquid meniscus", J. Exp. Therm. Fluid Science, Vol. 26, pp. 157-162.

Howard, A., and Mudawar, I., 1999, "Orientation effects on pool boiling critical heat flux (CHF) and modeling of CHF for near vertical surfaces”, Int. J. Heat Mass Transfer, Vol. 42, pp. 1665-1688.

Kandlikar, S., Shoji, M., and Dhir, V., 1999, "Handbook of Phase Change", Taylor and Franci.s.

Kataoka, I. and Serizawa, A., 1990, "Interfacial area concentration in bubbly flow”, Nucl. Eng. Design, Vol. 120, pp. 163-180.

Kenning, D. and Yan, Y., 1996, "Pool boiling heat transfer on a thin plate: features revealed by liquid crystal thermography", Int. J. Heat Mass Transfer, Vol. 39, pp. 3117-3137.

Kleen, U., 1984, "Üntersuchungen zum Übergangssieden von strömendem Wasser an elektrisch erwärmten Heizflächen mit temperturgeregelter Wärmezufuhr", $\mathrm{PhD}$ thesis, Technische Universität Berlin, Germany.

Lüttich, T., Marquardt, W., Buchholz, M., and Auracher, H., 2004 "Towards a unifying heat transfer correlation for the entire boiling curve", Int. J. Thermal Sciences, accepted for publication.

Lüttich, T., Marquardt, W., Buchholz, M., and Auracher, H., 2005,

"Identification of unifying het transfer mechanisms along the entire boiling curve “, Int. J. Thermal Sciences, p. accepetde for publication.

Mitrovic, J., 1985, "Wärmetrnsport in der Umgebung einer wachsenden

Dampfblase", Wärme und Stoffübertragung, Vol. 19, pp. 47-52.

Nishio, S., Gotoh, T., and Nagai, N., 1998, "Observation of boiling structures in high heat flux boiling", Int. J. Heat Mass Transfer, Vol. 41, pp 391-3201.

Pinto, A., Gorenflo, D., and Künstler, W., 1996, "Heat transfer and bubble formation with pool boiling of propane at a horizontal copper tube". In: Proc. $2^{\text {nd }}$ Europ. Therm. Sci. Conf. ETS, Vol. 3, pp. 1643-1660, Pisa.

Sadasivan, P., Unal, C., and Nelson, R., 1995, "Perspective: Issues in CHF modeling - the need for new experiments", ASME J. of Heat Transfer, Vol. 117, pp. 558-567.

Skritek, P., 1998, Handbuch der Audio Schaltunhstechnik, Franzis, München.

Stephan, P., and Hammer, J., 1994, “A new model for nucleate boiling heat transfer", Wärme-und Stoffübertragung, Vol. 30, pp. 119-125.

Ungar, E., and Eichhorn, R., 1996, "Transition noiling curves in saturated pool boiling from horizontal cylinders", J. Heat Transfer, Vol. 118, pp. 654-661.

Wayner, Jr., P., 1994, "Thermal and mechanical effects in the spreading of a liquid film due to a change in the apparent finite contact angle", J. Heat Transfer, Vol. 116, pp. 938-945.

Witte, L and Lienhard, J., 1982 "On the existence of two transition boiling curves”, Int. J. Heat and Mass Transfer, Vol. 25, pp. 771-779.

Zuber, N., 1958, "On the stability of boiling heat transfer", ASME J.

Heat Transfer, Vol. 80, pp. 711-720. 